\title{
Chronic Sleep Restriction Disrupts Sleep Homeostasis and Behavioral Sensitivity to Alcohol by Reducing the Extracellular Accumulation of Adenosine
}

\author{
Jerome Clasadonte, ${ }^{1 \star}$ Sally R. McIver, ${ }^{1 *}$ Luke I. Schmitt, ${ }^{1 \star}$ Michael M. Halassa, ${ }^{2}$ and Philip G. Haydon ${ }^{1}$ \\ ${ }^{1}$ Department of Neuroscience, Tufts University School of Medicine, Boston, Massachusetts 02111, and ${ }^{2}$ New York University, Neuroscience Institute, New \\ York, New York 10016
}

\begin{abstract}
Sleep impairments are comorbid with a variety of neurological and psychiatric disorders including depression, epilepsy, and alcohol abuse. Despite the prevalence of these disorders, the cellular mechanisms underlying the interaction between sleep disruption and behavior remain poorly understood. In this study, the impact of chronic sleep loss on sleep homeostasis was examined in C57BL/6 $\mathrm{J}$ mice following $3 \mathrm{~d}$ of sleep restriction. The electroencephalographic power of slow-wave activity (SWA; $0.5-4 \mathrm{~Hz}$ ) in nonrapid eye movement (NREM) sleep and adenosine tone were measured during and after sleep restriction, and following subsequent acute sleep deprivation. During the first day of sleep restriction, SWA and adenosine tone increased, indicating a homeostatic response to sleep loss. On subsequent days, SWA declined, and this was accompanied by a corresponding reduction in adenosine tone caused by a loss of one source of extracellular adenosine. Furthermore, the response to acute sleep deprivation $(6 \mathrm{~h})$ was significantly attenuated in sleep-restricted mice. These effects were long-lasting with reduced SWA and adenosine tone persisting for at least 2 weeks. To investigate the behavioral consequences of chronic sleep restriction, sensitivity to the motor-impairing effects of alcohol was also examined. Sleep-restricted mice were significantly less sensitive to alcohol when tested $24 \mathrm{~h}$ after sleep restriction, an effect that persisted for 4 weeks. Intracerebroventricular infusion of an adenosine A1 receptor antagonist produced a similar decrease in sensitivity to alcohol. These results suggest that chronic sleep restriction induces a sustained impairment in adenosine-regulated sleep homeostasis and consequentially impacts the response to alcohol.
\end{abstract}

Key words: adenosine; alcohol; allostasis; EEG; hippocampus; sleep

\section{Introduction}

Sleep disorders are prevalent worldwide and account for $\$ 15.9$ billion annually in treatment and reduced productivity in the U.S. (National Center for Sleep Disorders). Treatments for sleep disorders have variable efficacies, most likely resulting from the multitude of environmental and genetic variables known to influence the development of chronic sleep impairments. For the same reason, it has been difficult to identify the cellular mechanisms that contribute to sleep impairments. Sleep is regulated by two fundamental processes - a circadian process that is entrained by environmental factors such as light or food, and a homeostatic process, which provides the drive for sleep in response to prior wakefulness (sleep pressure; Borbély and Achermann, 1999). Increased sleep drive in response to sleep deprivation results in

Received June 14, 2012; revised Dec. 17, 2013; accepted Dec. 21, 2013.

Author contributions: J.C., S.R.M., L.I.S., and P.G.H. designed research; J.C., S.R.M., and L.I.S. performed research; J.C., S.R.M., and L.I.S. analyzed data; J.C., S.R.M., L.I.S., M.M.H., and P.G.H. wrote the paper.

This work was funded by the NIH/NIAAA Grant F32 AA019902 to S.R.M. and Grants R01AA020183 and R01NS037585-17 to P.G.H.; NIH/NIDA Grant DA025967 to P.G.H., J.C. was supported by the Epilepsy Foundation.

The authors declare that P.G.H. has equity interest in GliaCure, Inc.

*J.C., S.R.M., and L.I.S. contributed equally to this work.

Correspondence should be addressed to Dr Philip G. Haydon, Department of Neuroscience, Tufts University School of Medicine, 136 Harrison Avenue, Boston, MA 02111. E-mail: philip.haydon@tufts.edu.

DOI:10.1523/JNEUROSCI.2870-12.2014

Copyright $\odot 2014$ the authors $\quad 0270-6474 / 14 / 341879-13 \$ 15.00 / 0$ increased sleep time and/or intensity in recovery sleep (Tononi and Cirelli, 2006). Despite the tight regulation of sleep, chronic sleep loss, which is often associated with work-related demands, can lead to long-lasting impairments in cognitive functions (Banks and Dinges, 2007; McCoy and Strecker, 2011). For example, chronic sleep loss has been shown to induce sustained cognitive impairments, despite subjective reporting of sleepiness dissipating over time (Van Dongen et al., 2003). The mechanism underlying this consequence of chronic sleep restriction is unknown.

Impairments in sleep homeostasis are also associated with several psychiatric conditions including alcohol abuse and dependence (Brower, 2003; Armitage, 2007; Cirelli, 2009; Wulff et al., 2010). Childhood sleep disturbances have been associated with increased propensity to abuse alcohol later in life (Wong et al., 2010), and alcohol is often used as self-medication among insomniacs (Brower et al., 2001). Sleep disturbances are especially severe in recovering alcoholics and are a primary contributor to relapse (Brower et al., 2011). The bidirectional influence of sleep disruptions and alcohol behaviors, though prominent, remains poorly understood.

Given the prevalence of sleep impairments, the mechanisms underlying the homeostatic response to chronic sleep loss and related behavioral consequences require further investigation. In 
this study, we used intermittent treadmill activity to restrict sleep (Bjorness et al., 2009) and examined the effects of chronic sleep loss on sleep homeostasis and related behaviors. Although acute sleep deprivation caused a homeostatic increase in nonrapid eye movement (NREM) slow-wave activity (SWA; 0.5-4 Hz) and adenosine-dependent inhibition of synaptic activity (adenosine tone), chronic sleep restriction ( $3 \mathrm{~d}$ ) caused an allostatic reduction in both of these parameters and attenuated the response to acute sleep deprivation. This allostatic response was sustained for 2 weeks following sleep restriction. The reduced adenosine tone was not due to increased clearance because blocking adenosine transport had no effect in sleep-restricted mice, suggesting that sleep loss affects active delivery of extracellular adenosine. Given the association between sleep disruptions and alcohol exposure, and because alcohol can impact adenosine signaling (Nam et al., 2012), we asked whether sleep perturbations modified the behavioral response to acute alcohol exposure. We found that sleep restriction induces a long-lasting decrease in sensitivity to the motor-impairing effects of alcohol, an effect mimicked by chronic blockade of adenosine A1 receptors (A1Rs).

\section{Materials and Methods}

Animals. Adult male mice (aged 6-12 weeks old) maintained on the C57BL/6J line were used for these experiments. Mice were housed on a $12 \mathrm{~h} \mathrm{light/dark}$ cycle and given standard chow and water ad libitum. These experiments were performed with the approval of the Tufts University Institutional Animal Care and Use Committee, and under the guidelines defined by the National Institutes of Health Guide for the Care and Use of Laboratory Animals.

Chronic sleep restriction. Mice were placed in individual Plexiglas chambers ( 46 inches $^{2} \times 1^{\prime} 1$ inch high) on top of a treadmill housed in a soundproof chamber, and allowed $\sim 1$ week to acclimate. Food and water was available ad libitum in hoppers attached to the sides of the chambers. Sleep restriction began at the onset of the light cycle [zeitgeiber time (ZT)0; subjective nighttime), and was implemented using $6 \mathrm{~h}$ cycles consisting of $4 \mathrm{~h}$ of treadmill on (speed of $3.33 \mathrm{~cm} / \mathrm{s}$ ) and $2 \mathrm{~h}$ of treadmill off, four times per day for $3 \mathrm{~d}$. Undisturbed mice (nonsleep-restricted group) housed in the same soundproof chamber were used as controls. These parameters were based on a previous report using intermittent treadmill activity to restrict sleep (Bjorness et al., 2009).

Electroencephalogram/electromyogram implantation surgery. Mice were anesthetized with isoflurane and placed into a stereotaxic frame. For implantation of electroencephalogram (EEG) electrodes, the skull surface was exposed and four insulated wire electrodes were placed and screwed as follows: two extradural cortical electrodes were inserted bilaterally in the frontal areas and the other two were inserted bilaterally in the parietal areas. For implantation of electromyogram (EMG), two insulated wire electrodes were inserted bilaterally into the nuchal muscle. Electrodes connected to a microconnector were secured at the surface of the skull with dental acrylic. After surgery, mice were intraperitoneally injected with buprenorphine $(0.08 \mathrm{mg} / \mathrm{kg})$ and lactated Ringer's solution, and fed moistened rodent food. After $5 \mathrm{~d}$ of postoperative recovery, lightweight recording cables were connected to the head implants and mice were placed on a treadmill in individual bottomless Plexiglas cages containing water and food ad libitum and acclimated for a week, as described above. EEG and EMG signals were bandpass filtered at 0.3-100 $\mathrm{Hz}$ and $10-100 \mathrm{~Hz}$, respectively, using a 15 LT Bipolar Physiodata amplifier system (Grass Technologies), sampled at $200 \mathrm{~Hz}$ with a MP150 data acquisition system (BIOPAC Systems) and stored on a personal computer. Following acclimation, EEG/EMG activity was continuously monitored for 6 d. Baseline EEG/EMG activity starting at ZT0 was measured for $24 \mathrm{~h}$ (baseline), followed by $72 \mathrm{~h}$ of sleep restriction (3 d: SR1, SR2, and SR3). Following sleep restriction, recovery EEG/EMG activity was monitored for $24 \mathrm{~h}$. For the acute sleep deprivation after sleep restriction procedure (see Fig. 4A), the treadmill was engaged for 6 more hours (from ZT0 to ZT6) beginning $24 \mathrm{~h}$ and/or 2 weeks after termination of sleep restriction. EEG/EMG activity was monitored during the $6 \mathrm{~h}$ of sleep deprivation and $18 \mathrm{~h}$ of recovery sleep. Sleep-deprived mice housed on the treadmill but not subjected to $3 \mathrm{~d}$ of sleep restriction (nonsleep-restricted group) were used as controls.

Vigilance state scoring and analysis. Sleep stages were scored visually based on $4 \mathrm{~s}$ epochs by a trained experimenter using SleepSign for Animal software (Kissei Comtec). Wakefulness (W) consisted of low-amplitude, high-frequency EEG and high EMG activity; rapid eye movement (REM) sleep consisted of low-amplitude, desynchronized EEG with low EMG activity; and NREM sleep consisted of high-amplitude, low-frequency EEG with little EMG modulation. Brief awakenings defined as uninterrupted waking episodes of $1-4 \mathrm{~s}$ epochs were not included in the analysis. Epochs containing movement artifacts were included in the state totals, but excluded from subsequent spectral analysis. After assignments of state scores, the amount of each state (expressed as a percentage of the total recording time in $1 \mathrm{~h}$ time bins) and their duration were measured. During the $6 \mathrm{~h}$ acute sleep-deprivation procedure, NREM sleep latency was defined as the time that elapsed between the beginning of the $18 \mathrm{~h}$ of recovery sleep and the first NREM sleep episode. EEG power spectra of consecutive $4 \mathrm{~s}$ epochs (fast Fourier transform routine; Hanning window) were calculated. The EEG power during NREM sleep from 0.5 to $4.0 \mathrm{~Hz}$ was defined as SWA and was used as a quantitative measure of sleep pressure and homeostatic sleep drive (Steriade, 2005). The EEG power of SWA during NREM sleep recorded for the six consecutive days was expressed as a percentage of the individual mean SWA power in NREM sleep over the entire $24 \mathrm{~h}$ of the baseline period, except where otherwise noted. This transformation was conducted to correct for individual differences in the absolute power.

Acute hippocampal slice preparation. Mice were anesthetized using isoflurane, decapitated, and the brain was then rapidly extracted in ice-cold cutting solution containing the following (in $\mathrm{mm}$ ): $124 \mathrm{NaCl}, 26$ $\mathrm{NaHCO}_{3}, 1 \mathrm{NaHPO}_{4}, 10$ glucose, 1 sodium pyruvate, 0.6 ascorbate, 2.9 $\mathrm{KCl}, 1 \mathrm{CaCl}_{2}$, and $2 \mathrm{MgCl}_{2}$, pH 7.4 (with $\mathrm{O}_{2} 95 \%, \mathrm{CO}_{2} 5 \%$ ). Horizontal sections of the hippocampus ( $310 \mu \mathrm{m}$ thick) were cut using a vibratome (VT 1200S; Leica) in oxygenated ice-cold cutting solution, and then transferred to a $30^{\circ} \mathrm{C}$ chamber of oxygenated cutting solution for recovery incubation of $\sim 1.5 \mathrm{~h}$. For all slice experiments, ZT corresponds to the time of sacrifice.

Extracellular recordings. Following recovery incubation, a hippocampal slice was transferred to a recording chamber continuously superfused at $1.2 \mathrm{ml} / \mathrm{min}$ with artificial CSF (aCSF) containing the following (in $\mathrm{mm}): 124 \mathrm{NaCl}, 26 \mathrm{NaHCO}_{3}, 1 \mathrm{NaHPO}_{4}, 10$ glucose, 1 sodium pyruvate, $2.9 \mathrm{KCl}, 2 \mathrm{CaCl}_{2}$, and $1 \mathrm{MgCl}_{2}, \mathrm{pH} 7.4$ (with $\mathrm{O}_{2} 95 \%, \mathrm{CO}_{2} 5 \%$ ). The CA1-CA2 boundary was severed to minimize recurrent activity, and a glass electrode containing aCSF was positioned in area CA1 for field EPSP (fEPSP) recordings. The signal was amplified and bandpass filtered between $0.1 \mathrm{~Hz}$ and $1 \mathrm{kHz}$ using a 1800 microelectrode amplifier (A-M Systems) and digitized at $5 \mathrm{kHz}$ using a Digidata 1320 digitzer (Molecular Devices). All recordings were made at $32.8^{\circ} \mathrm{C}$. Paired current pulses were delivered using a $125 \mu \mathrm{m}$ concentric platinum-iridium electrode in the stratum radiatum to orthodromically stimulate axons entering area CA1. Stimulation and recording sweeps were made at $0.033 \mathrm{~Hz}$ frequency. Recordings were stored using Clampex 9.2 software and analyzed using Clampfit software (Molecular Devices).

Measurement of tonic adenosine A1R-mediated-inhibition (adenosine tone) and equilibrative adenosine transport. The slope of the fEPSP was measured at the CA3-CA1 Schaeffer collateral synapse, and stimulus intensity/response curves were plotted for each slice using stimulating currents of increasing intensity ranging from 25 to $200 \mu \mathrm{A}$ in $25 \mu \mathrm{A}$ intervals ( 5 pulses per intensity). The maximum slope obtained was used to estimate the point of saturation, and the stimulus intensity required to produce half the maximum slope was estimated and used as the stimulation intensity for the baseline and subsequent recordings. Input/output scatterplots were made by plotting the fEPSP slope at increasing stimulation intensities against the peak amplitude of the fiber volley. Input/ output curve slopes for each slice were determined using a linear regression fit. Paired pulse recordings were made throughout the experiment with an interstimulus interval of $25 \mathrm{~ms}$ within each sweep. After a $30 \mathrm{~min}$ baseline period at half-maximal stimulation, the adenosine A1R-mediated inhibitory tone was measured by perfusing the slice 
with the A1R antagonist 8-cyclopentyl-1,3-dimethylxanthine (CPT; 200 nм; Sigma-Aldrich) and measuring the alleviation of inhibition according to the following equation: adenosine tone $=([$ fEPSP.cpt-fEPSP.acsf $] /$ fEPSP.acsf). The concentration of CPT used was chosen because it is consistent with previous studies (Arrigoni et al., 2001; Halassa et al., 2009; Schmitt et al., 2012) and is considered to be selective in this range for A1R $(\mathrm{Ki}=10.9 \mathrm{~nm})$ over A2R ( $\mathrm{Ki}=1440 \mathrm{~nm}$; Bruns, 1981). Sensitivity to A1R activation was estimated in situ using the A1R-specific agonist 2-chloro-N(6)-cyclopentyladenosine (CCPA; Sigma-Aldrich) applied to increasing concentrations at 15 min intervals. Passive transport of adenosine was measured indirectly by blocking the equilibrative nucleoside transporter 1 (ENT1) using the transport inhibitor 6-S-[(4-Nitrophenyl) methyl]-6-thioinosine (NBMPR, $100 \mathrm{~nm}$; Tocris Bioscience). This concentration was chosen based on previous studies showing that it was sufficient to inhibit synaptic transmission through elevation of adenosine (Pascual et al., 2005). Following a 15 min baseline, NBMPR was applied for $20 \mathrm{~min}$ and then washed out for at least $20 \mathrm{~min}$. To determine whether the effect of NBMPR depended on A1Rs, these experiments were repeated in the presence of the A1R antagonist CPT (200 nM). In these experiments, CPT was applied for $30 \mathrm{~min}$ before the baseline recording after which the experiment was conducted using the same procedure as described above.

Acute sleep deprivation for probing adenosine regulation of sleep homeostasis. Mice were acutely sleep-deprived $(6 \mathrm{~h})$ beginning at the onset of the light cycle (ZT0) using gentle handling. Briefly, mice were transferred to a new cage and monitored throughout the sleep deprivation period for signs of sleep (extended periods of inactivity, adoption of sleep posture) by an observer. Mild stimuli were used to prolong wakefulness, including rotating the cage, disassembling or removing the bedding, or placing a nitrile glove in the corner of the cage and gently brushing the animal with the glove (Halassa et al., 2009; Schmitt et al., 2012).

Assessment of alcohol sensitivity. Acute sensitivity to the motorimpairing effects of alcohol was measured following intraperitoneal (i.p.) administration of ethanol ( $2.0 \mathrm{~g} / \mathrm{kg} ; 20 \mathrm{ml} / \mathrm{kg}$ volume). Mice were first trained to walk on a rotarod apparatus at a speed of $22 \mathrm{rpm}$ until they were able to reach an arbitrary baseline of $60 \mathrm{~s}$ (latency to fall $>60 \mathrm{~s}$ ). The following day, mice were tested again to confirm a baseline performance of $60 \mathrm{~s}$, then injected with ethanol and returned to their home cages. The latency to fall was measured $15,30,45,60$, and 80 min postinjection, and performance was plotted based on percentage of baseline performance. There was no difference in baseline performance between sleep restricted and nonsleep-restricted mice.

Measurement of blood alcohol content. At the end of the rotarod tests ( $\sim 90$ min after the alcohol injection), blood samples were obtained using submandibular puncture and quickly placed on ice. Blood serum was isolated and further analyzed for blood alcohol content using the Ethanol Assay (Sekisui/Genzyme Diagnostics). Analysis was performed according to the manufacturer's protocol.

In vivo pharmacology. Alzet micro-osmotic pumps (Model 1002; flow rate $0.24 \mu \mathrm{l} / \mathrm{h}$; DURECT) were filled with the A1R antagonist 8-Cyclopentyl-1,3-dipropylxanthine (DPCPX, $100 \mu \mathrm{M}$; Sigma-Aldrich;) or vehicle $(0.1 \%$ DMSO in aCSF), sealed off with a closed flow moderator and incubated overnight in $0.9 \%$ saline. Immediately before surgery, the catheter and brain infusion cannula (DURECT) were primed with DPCPX or vehicle and connected to the pump and flow moderator, according to the manufacturer's instructions. One pump per animal was subcutaneously implanted along the left dorsal side of the anesthetized mouse and the cannula was stereotaxically targeted to the left cerebral ventricle $(\mathrm{A} / \mathrm{P},-0.6 \mathrm{~mm} ; \mathrm{M} / \mathrm{L},-0.5 \mathrm{~mm})$, and secured with dental cement. The scalp was sutured over the cannula implant and mice were monitored daily thereafter. Mice were trained and tested on the rotarod 10-12 d after surgery.

Statistical analysis. SigmaStat was used to perform all statistical analysis. Comparisons between two groups were conducted with the unpaired and paired Student's $t$ test or the nonparametric Mann-Whitney $U$ test as appropriate. The difference between several groups was analyzed by oneway ANOVA. Two-way ANOVA was used when comparisons involving more than one experimental variable were made. Repeated-measures ANOVAS were used when multiple measurements were made over time in the same groups. ANOVA was followed by a Student-Newman-Keuls (SNK), Bonferonni, or Tukey's HSD (honestly significant difference) post hoc multiple-comparisons test as appropriate. For adenosine tone measurements (nonparametric data), Kruskal-Wallis ANOVA tests were performed followed by pairwise comparison testing using the MannWhitney $\mathrm{U}$ post hoc test. To measure the $50 \%$ recovery rate, data from 15-80 min after alcohol injection was fit to a sigmoidal curve and the V50 was calculated using GraphPad Prism 5. For data that were not normally distributed, the values were statistically transformed to rank data for comparison. Estimation of A1R sensitivity was made by fitting the Hill equation to the normalized fEPSP slope at each concentration using MATLAB computing software (Mathworks). Statistical significance was defined at $p<0.05$. Data are presented as mean \pm SEM.

\section{Results}

\section{Intermittent treadmill activity effectively restricts sleep and disrupts sleep architecture}

After 1 week acclimation to the treadmill, hypnograms obtained from EEG/EMG monitoring on the baseline day indicated normal sleep architecture, with mice primarily sleeping during the light phase (Fig. 1A-C). Throughout the $3 \mathrm{~d}$ of intermittent treadmill activity, however, sleep was almost exclusively restricted to each $2 \mathrm{~h}$ period when the treadmill was not active (Fig. $1 A-C, \mathrm{OFF}$ ), with amount of time spent in NREM, REM and total sleep (NREM + REM sleep) reduced by $58.03 \%, 47.74 \%$, and $56.87 \%$, respectively (Fig. 1D-F). Compared with baseline, there was a moderate but significant increase in total sleep time, accounted for solely by NREM sleep, during the recovery day following sleep restriction (Fig. 1D-F). Collectively, these results demonstrate that intermittent treadmill activity alters overall sleep architecture and serves as an effective method of sleep restriction.

\section{Chronic sleep restriction impairs the wakefulness-induced homeostatic increase in SWA}

The spectral power of the EEG in the frequency range of SWA (0.5-4 Hz) during NREM sleep provides a direct metric for sleep need; it increases during normal wakefulness and with extended wakefulness (sleep deprivation; Steriade and McCarley, 2005). Slow oscillations are thought to be driven by local neocortical circuitry, and therefore, are dependent on intracortical synaptic strength (Fellin et al., 2009). Given that homeostatic sleep drive is intimately related to wake-dependent synaptic potentiation (Hanlon et al., 2011), the cortical slow oscillation is considered a readout for sleep homeostasis (Vyazovskiy et al., 2008, 2009). During the first day of sleep restriction, there was a significant increase in the power of SWA in NREM sleep recorded during treadmill-off (TM-off) periods (Fig. $2 A-C$ ), consistent with accumulated sleep pressure during enforced wakefulness; this increase was significantly attenuated during the subsequent days of sleep restriction and returned to baseline on the recovery day (Fig. 2A-C). Though SWA power was unaltered in REM sleep (data not shown), it was moderately increased during wake (Fig. $2 D-G$ ), especially when the treadmill was active (Fig. $2 F, G$; TMon), suggesting that sleep restriction induced breakthrough sleep, or SWA leakage during periods of enforced wakefulness, consistent with previous studies (Leemburg et al., 2010). There was also a significant increase in theta power $(6-10 \mathrm{~Hz})$ during wake throughout the course of sleep restriction (Fig. 2F; TM-on). Because wake was enforced using the treadmill, this is likely a result of continuous motor activity, which is known to be associated with theta power (Vanderwolf, 1969; Whishaw, 1972).

Because the progressive attenuation in the increases of NREM SWA during the $2 \mathrm{~h}$ sleep opportunities (TM-off) could result from a compensatory increase in SWA accumulated across the $4 \mathrm{~h}$ 

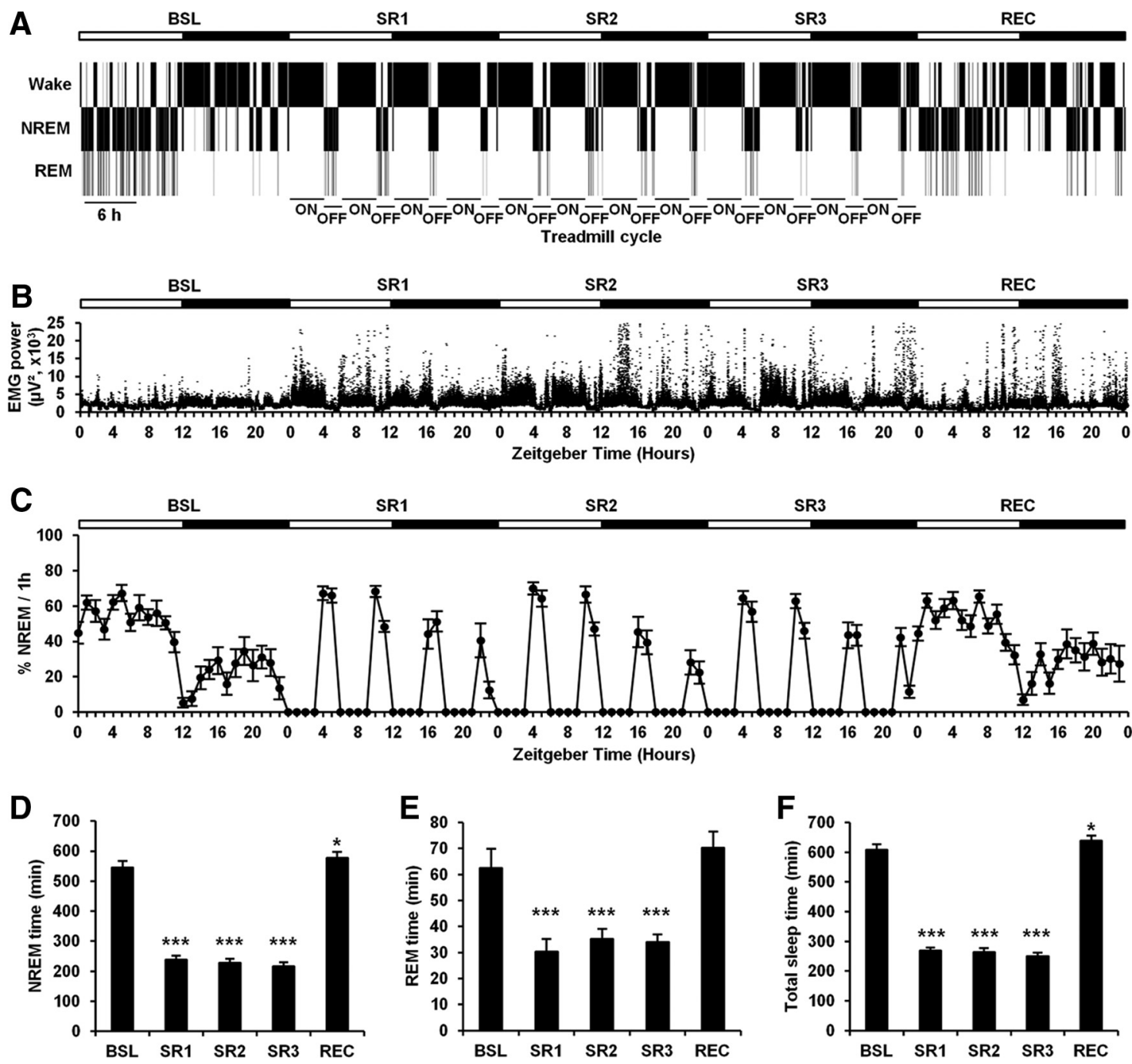

Figure 1. Chronic sleep restriction affects sleep architecture. $A$, Representative hypnogram of a mouse housed on a treadmill during baseline day (BSL), three consecutive days of sleep restriction (SR1, SR2, and SR3) and recovery day (REC). The slow-moving treadmill was on for $4 \mathrm{~h}(\mathrm{ON})$ and off for $2 \mathrm{~h}$ (OFF) for a total of 12 complete $6 \mathrm{~h}$ cycles. Mice were maintained on a $12 \mathrm{~h} \mathrm{light}$ (open $12 \mathrm{~h}$ horizontal bar)/dark (filled $12 \mathrm{~h}$ horizontal bar). Note the disruption of the diurnal pattern of the NREM sleep during the three consecutive days of sleep restriction compared with the BSL and REC days. $\boldsymbol{B}$, Analysis of EMG power from the mouse presented in $\boldsymbol{A}$. Note the increase in EMG power during the corresponding periods of spontaneous and enforced wakefulness. $\boldsymbol{C}$, Percentage average of the time spent in NREM sleep per hour during the $5 \mathrm{~d}$ of the experiment on the treadmill ( $n=11$ animals). $\boldsymbol{D}, \boldsymbol{E}$, Averaged amount of time spent in NREM sleep (D) and REM sleep (E) during each $24 \mathrm{~h}$ of the experiment $\left(\boldsymbol{D}\right.$, one-way repeated-measures ANOVA, $F=295.81, p<0.001$, SNK post hoc test, ${ }^{*} p<0.05,{ }^{* * *} p<0.001$ compared with BSL, $n=11$ animals; $\boldsymbol{E}$ : one-way repeated-measures ANOVA, $F=30.08, p<0.001$, SNK post hoc test, ${ }^{* * *} p<0.001$ compared with BSL, $n=11$ animals). $F$, The averaged amount of total sleep time (NREM + REM) during each $24 \mathrm{~h}$ of the experiment was significantly decreased during the $3 \mathrm{~d}$ period of chronic sleep restriction (one-way repeated-measures ANOVA, $F=350.06, p<0.001 ;$ SNK post hoc test, ${ }^{*} p<0.05$, ${ }^{* * *} p<0.001$ compared with BSL; $n=11$ animals). Error bars represent SEM.

enforced wakefulness procedure (TM-on), we computed the cumulative integrated SWA power throughout the $24 \mathrm{~h}$ of each day of the experiment (summed SWA power over all epochs during TM-off and TM-on periods) in NREM, wake and all vigilance states combined (Fig. $3 A-C$ ). We found that the cumulative integrated SWA in wake was similar across the $3 \mathrm{~d}$ of sleep restriction (Fig. 3A). Conversely, a cumulative loss of integrated SWA was observed during the $3 \mathrm{~d}$ of sleep restriction in NREM and it was significantly attenuated on the third day compared with the first (Fig. 3B). The progressive loss of cumulative integrated SWA during the $3 \mathrm{~d}$ of sleep restriction was conserved when values for integrated SWA power during both wake and REM were added to that for NREM (Fig. $3 C$ ). These data suggest that the attenuation in NREM SWA during the TM-off periods (Fig. $2 A-C$ ) was not a consequence of a compensatory increase in cumulative SWA during the course of sleep restriction periods (TM-on). In addition, we observed that the cumulative integrated SWA during the recovery day in wake, NREM and all vigilance states was significantly higher than during the baseline day (Fig. $3 A-C$ ), suggesting that some homeostatic sleep pressure did accumulate during the $3 \mathrm{~d}$ of sleep restriction and was then dissipated after the termination of sleep restriction.

Additionally, we computed the cumulative integrated SWA power throughout the entire experiment (before, during, and after chronic sleep restriction). The SWA during wake integrated over the entire experiment remained similar to the baseline projection throughout the sleep restriction (Fig. 3D). However, consistent with previous studies (Deurveilher et al., 2012), the loss of cumulative integrated SWA in NREM and all vigilance states remained parallel to the baseline projection following sleep restriction (Fig. 3E,F), suggesting that the dissipation of homeostatic sleep pressure seen during recovery (Fig. $3 A-C$ ) was not sufficient to recover the cumulative loss of integrated SWA after sleep restriction. Collectively these findings show that chronic sleep re- 
A

BSL SR1 SR2 SR3 REC

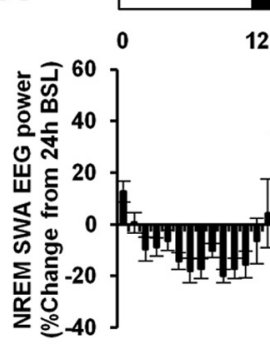

o

12 ${ }^{0}{ }_{\text {Zeitgeber Time (Hours) }}{ }^{0}$

12

\begin{tabular}{ccc}
\multicolumn{3}{c}{ REC } \\
\hline 0 & 12 & 0
\end{tabular}

B

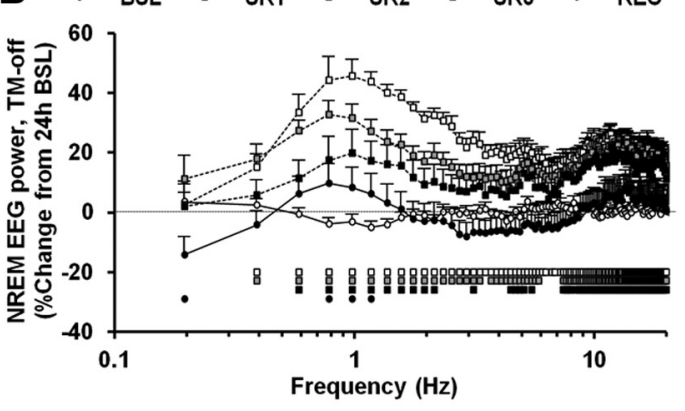

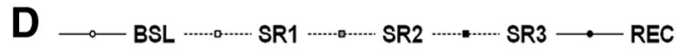

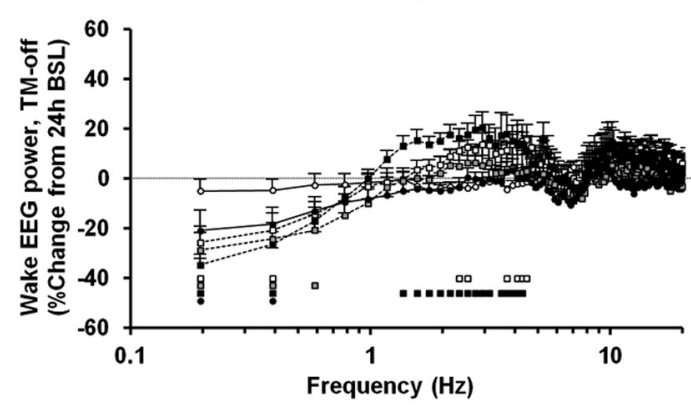

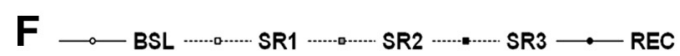

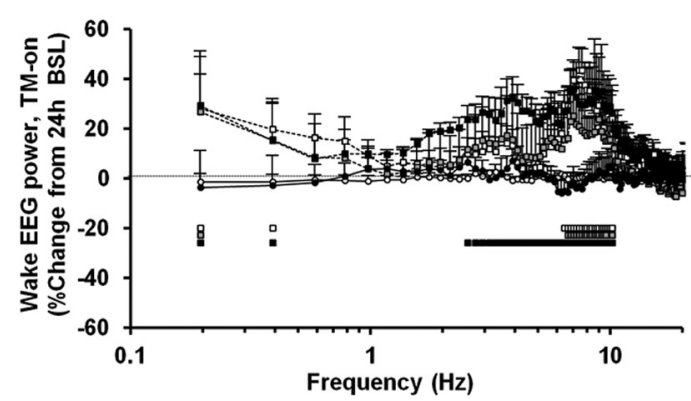

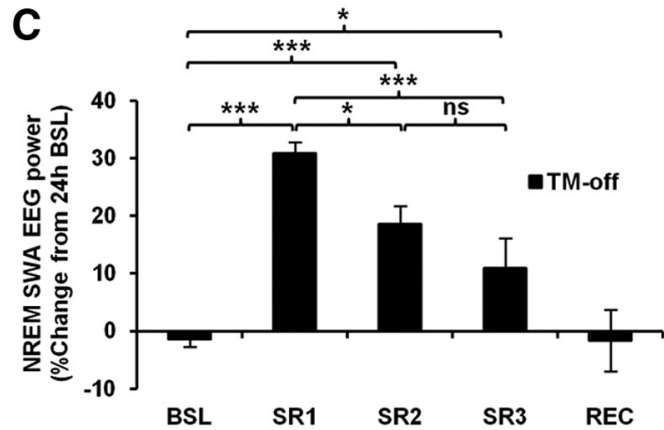

E

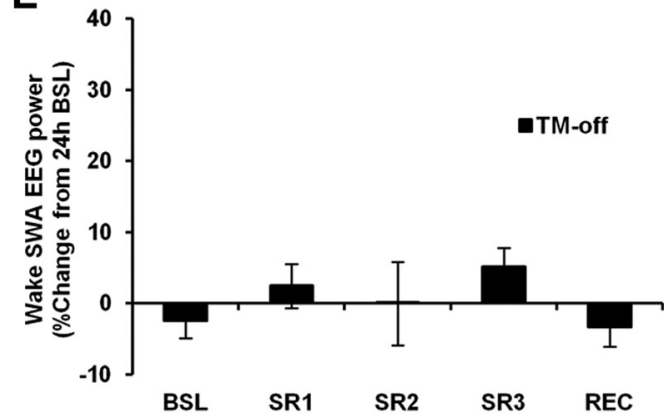

G

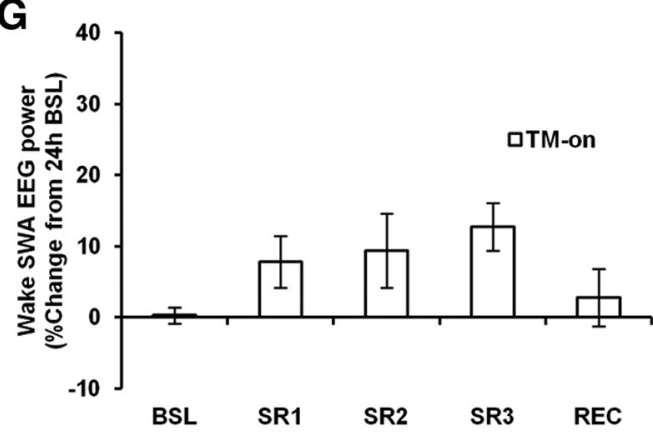

Figure 2. Effect of chronic sleep restriction on SWA.A, EEG power of SWA $(0.5-4 \mathrm{~Hz})$ during NREM sleep for each hour of the $5 \mathrm{~d}$ of the experiment on the treadmill plotted as percentage of $24 \mathrm{~h}$ mean values of the BSL day ( $n=11$ animals). $B$, NREM sleep EEG power during the total $8 \mathrm{~h} \mathrm{TM-off} \mathrm{periods} \mathrm{for} \mathrm{each} \mathrm{day} \mathrm{of} \mathrm{the} \mathrm{experiment} \mathrm{on} \mathrm{the} \mathrm{treadmill} \mathrm{plotted} \mathrm{as} \mathrm{percentage} \mathrm{of} 24 \mathrm{~h}$ mean values of the BSL day (two-way repeated-measures ANOVA: day, $F=6.84, p<0.001$; frequency, $F=6.28, p<0.001$; day $\times$ frequency, $F=4.60, p<0.001 ; n=11$ animals). Squares and circles at the bottom indicate frequencies that significantly differ from the BSL (SNK post hoc test, $p<0.05$ ). C, EEG power of SWA (percentage change from $24 \mathrm{~h} \mathrm{BSL}$ ) in NREM sleep during the total $8 \mathrm{~h}$ TM- off periods for each day of the experiment on the treadmill. SWA during the BSL and REC days were averaged over the corresponding total $8 \mathrm{~h}$ TM-off periods of each day of sleep restriction. Note the progressive attenuation in the increase of SWA over the $3 \mathrm{~d}$ of sleep restriction (one-way repeated-measures ANOVA, $F=17.69, p<0.001 ; \mathrm{SNK}_{\text {test, }}{ }^{*} p<0.05$, ${ }^{* * *} p<0.001 ; n=11$ animals; n.S., nonsignificant). $\boldsymbol{D}$, Wake EEG power during the total $8 \mathrm{~h} \mathrm{TM}$-off periods for each day of the experiment on the treadmill plotted as percentage of $24 \mathrm{~h}$ mean values of the BSL day (two-way repeated-measures ANOVA: day, $F=0.93, p>0.05$; frequency, $F=2.42, p<0.001$; day $\times$ frequency, $F=2.47, p<0.001 ; n=6$ animals). Squares and circles at the bottom indicate frequencies that significantly differ from the BSL (SNK post hoc test, $p<0.05$ ). $E$, EEG power of SWA (percentage change from $24 \mathrm{~h} \mathrm{BSL}$ ) in wakefulness during the total $8 \mathrm{~h}$ TM-off periods for each day of the experiment on the treadmill. SWA during the BSL and REC days were averaged over the corresponding total $8 \mathrm{~h} \mathrm{TM-offperiods} \mathrm{of} \mathrm{each} \mathrm{day} \mathrm{of} \mathrm{sleep} \mathrm{restriction} \mathrm{(one-way} \mathrm{repeated-measures} \mathrm{ANOVA,}$ $F=0.96, p>0.05, n=6$ animals). $F$, Wake EEG power during the total $16 \mathrm{~h} \mathrm{TM}$-on periods for each day of the experiment on the treadmill plotted as percentage of $24 \mathrm{~h}$ mean values of the BSL day (two-way repeated-measures ANOVA: day, $F=0.97, p>0.05$; frequency, $F=2.91, p<0.001$; day $\times$ frequency, $F=3.34, p<0.001 ; n=6$ animals). Squares at the bottom indicate frequencies that significantly differ from the BSL (SNK post hoc test, $p<0.05$ ). G, EEG power of SWA (percentage change from $24 \mathrm{~h} \mathrm{BSL}$ ) in wakefulness during the total $16 \mathrm{~h} \mathrm{TM}$-on periods for each day of the experiment on the treadmill. SWA during the BSL and REC days were averaged over the corresponding total $16 \mathrm{~h} \mathrm{TM}$-on periods of each day of sleep restriction (one-way repeated-measures ANOVA, $F=2.87, p>0.05, n=6$ animals). Error bars represent SEM. 

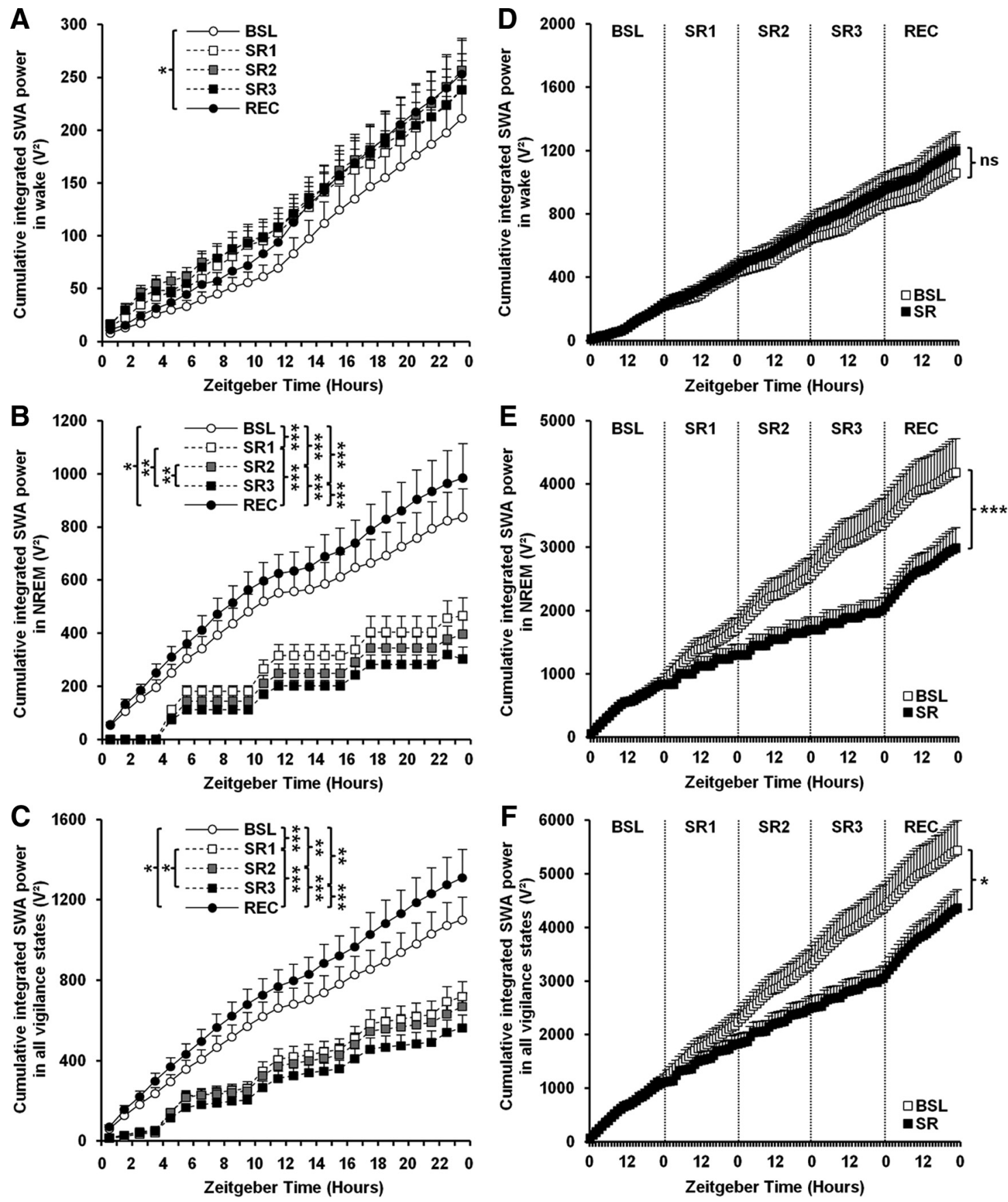

Figure 3. Cumulative loss of integrated SWA does not fully recover after chronic sleep restriction. $\boldsymbol{A}-\boldsymbol{C}$, Time course of integrated SWA over each $24 \mathrm{~h}$ period is shown in wake $(\boldsymbol{A})$, NREM (B), and all vigilance states (C). EEG power of SWA was cumulatively summed in $1 \mathrm{~h}$ bins over a $24 \mathrm{~h}$ period during the BSL, SR1, SR2, SR3, and REC days. $\boldsymbol{A}$-C, Asterisks indicate cumulative curves that significantly differ between days (two-way repeated-measures ANOVA followed by SNK post hoc test: ${ }^{*} p<0.05,{ }^{* *} p<0.01,{ }^{* * *} p<0.001 ; n=11$ animals). $\boldsymbol{D}-\boldsymbol{F}$, Time course of integrated SWA over the entire experiment in wake $(\boldsymbol{D})$, NREM $(\boldsymbol{E})$, and all vigilance states $(\boldsymbol{F})$. EEG power of SWA was cumulatively summed in $1 \mathrm{~h}$ bins over the $5 \mathrm{~d}$ of the chronic sleep restriction experiment (SR curve). The accumulation of integrated SWA over all days in the absence of chronic sleep restriction (BSL curve) represents an extrapolation of the empirical curves obtained on the BSL day. Note that the cumulative loss of integrated SWA during NREM $(\boldsymbol{E})$ and all vigilance states $(\boldsymbol{F})$ did not recover at the end of the REC day $(\boldsymbol{D}-\boldsymbol{F}$, two-way repeated-measures ANOVA followed by SNK post hoc test: ${ }^{*} p<0.05,{ }^{* * *} p<0.001, n=11$ animals per condition; n.s., nonsignificant). Error bars represent SEM.

striction alters sleep physiology and leads to an impairment of sleep homeostasis, marked by a dampening of sleep pressure or SWA accumulation.

To test whether the sleep homeostat could be reactivated following chronic sleep restriction, mice were subjected to acute sleep deprivation $(6 \mathrm{~h})$ following one day of recovery from sleep restriction (Fig. 4A). Six hours of treadmill activity effectively prolonged wakefulness in both previously undisturbed and sleep- restricted mice (data not shown), and induced an increase in SWA during recovery sleep, which was significantly attenuated in sleep-restricted mice (Fig. 4B). There was a trend toward increased latency to NREM sleep during the $18 \mathrm{~h}$ recovery after sleep deprivation but this effect was not significant (Fig. 4C). However, the increase in amount of NREM sleep time and NREM episode duration that characteristically occur during sleep rebound after prolonged wakefulness were significantly 
A
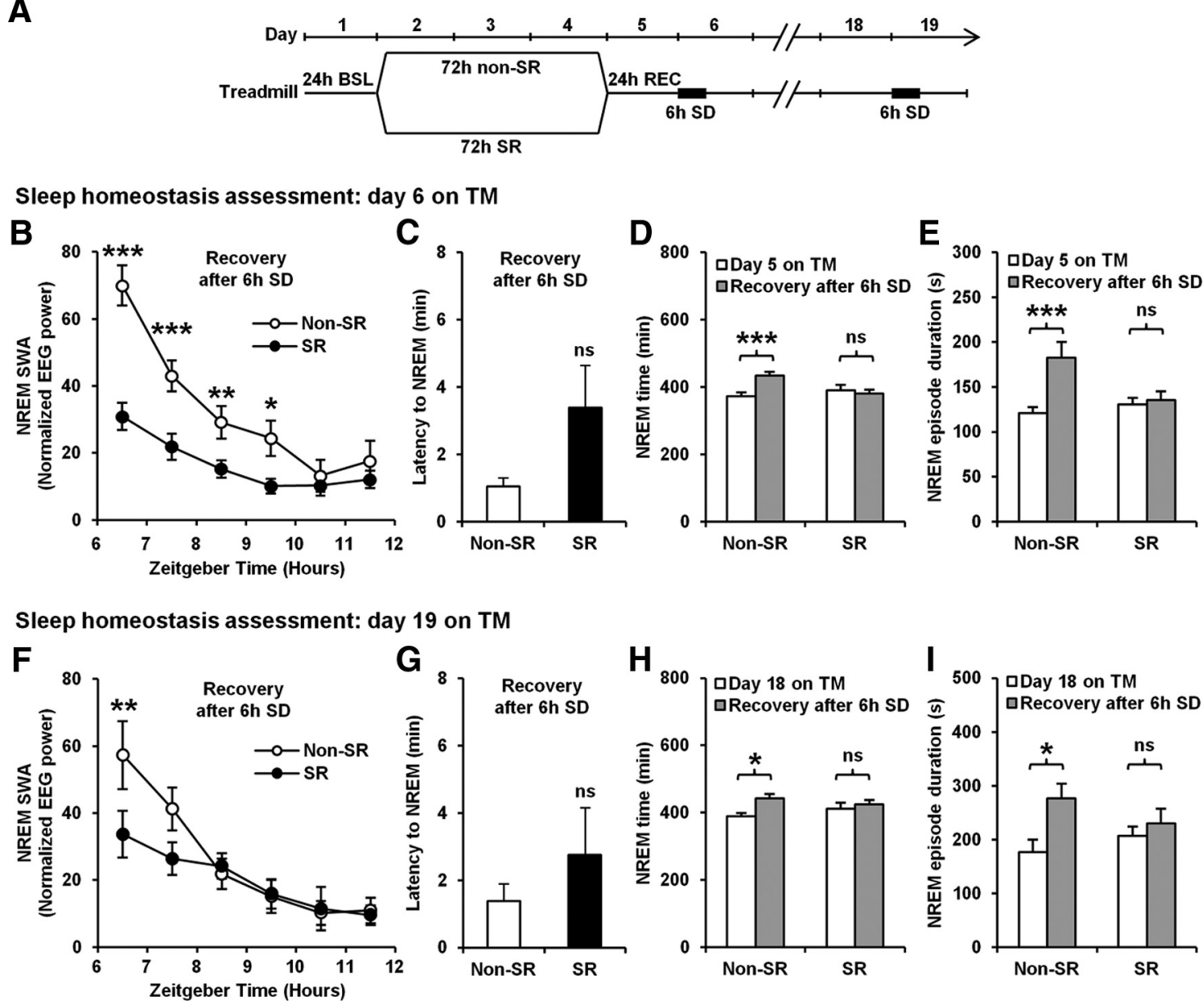

Figure 4. Effect of chronic sleep restriction on sleep homeostasis. $A$, Schematic showing the protocol for sleep deprivation (SD) after sleep restriction: mice were housed on a treadmill (TM) and monitored with cortical EEG. In the nonsleep-restricted (Non-SR) group, mice were left undisturbed on the TM while in the sleep-restricted (SR) group, mice were subjected to $3 \mathrm{~d}(72 \mathrm{~h})$ of restricted sleep. Assessment of sleep homeostasis was successively conducted on days 6 and 19 of the experiment for the non-SR group and after $24 \mathrm{~h}$ and 2 weeks of recovery for the SR group. Both non-SR and SR mice were sleep deprived for $6 \mathrm{~h}$ on the TM starting at ZTO and then allowed to recover for the following $18 \mathrm{~h}$. B-E, Assessment of sleep homeostasis on day 6. $\boldsymbol{B}$, Following SD, the increase in SWA power during NREM sleep, expressed as percentage of last $4 \mathrm{~h}$ of the light phase during day 5 was significantly smaller in the SR animals compared with the non-SR animals (two-way repeated-measures ANOVA: condition, $F=13.50, p<0.001$; time, $F=41.45, p<0.001$; condition $\times$ time, $F=8.02, p<0.001$; SNK post hoc test, ${ }^{*} p<0.05,{ }^{* *} p<0.01,{ }^{* * *} p<0.001 ; n=16$ animals per condition). C, Average latency to NREM sleep after SD in non-SR and SR animals (Mann-Whitney $U$ test: $U=$ $98.50, p>0.05, n=16$ animals per condition; n.s., nonsignificant). $\boldsymbol{D}-\boldsymbol{E}$, SD increased both the amount of time spent in NREM sleep (D) and duration of NREM episodes (E) in non-SR group but not in SR group during the $18 \mathrm{~h}$ recovery period compared with the corresponding $18 \mathrm{~h}$ of day 5 ( $\boldsymbol{D}$ : non-SR group, paired Student's $t$ test, $t=-4.58$, ${ }^{* * *} p<0.001 ; S R$ group, paired Student's $t$ test, $t=0.80, p>0.05, n=16$ mice per group; $E$ : non-SR group, paired Student's $t$ test, $t=-4.29, * * * p<0.001 ;$ SR group, paired Student's $t$ test, $t=-0.56$, $p>0.05, n=16$ animals per group; n.s., nonsignificant). $\boldsymbol{F}-\boldsymbol{I}$, Assessment of sleep homeostasis on day 19 . $\boldsymbol{F}$, Following SD, the increase in SWA power during NREM sleep, expressed as percentage of last $4 \mathrm{~h}$ of the light phase during day 18 was significantly smaller in the SR animals compared with the non-SR animals (two-way repeated-measures ANOVA: condition, $F=1.34, p>0.05 ;$ time, $F=16.78, p<0.001$; condition $\times$ time, $F=2.46, p<0.05$; SNK post hoc test, ${ }^{* *} p<0.01 ; n=6$ animals per condition). $G$, Average latency to NREM sleep after SD in non-SR and SR animals (unpaired Student's $t$ test: $t=-0.91, p>0.05, n=6$ animals per condition). $\boldsymbol{H}-\boldsymbol{I}$, SD increased both the amount of time spent in NREM sleep (H) and duration of NREM episodes $(\boldsymbol{I})$ in non-SR group but not in SR group during the $18 \mathrm{~h}$ recovery period compared with the corresponding $18 \mathrm{~h}$ of day 18 (H: non-SR group, paired Student's $t$ test, $t=-2.86,{ }^{*} p<0.05$; SR group, paired Student's $t$ test, $t=-1.55, p>0.05, n=6$ mice per group; $I$ : non-SR group, paired Student's $t$ test, $t=-3.33,{ }^{*} p<0.05 ; S R$ group, paired Student's $t$ test, $t=-1.60, p>0.05, n=6$ animals per group). Error bars represent SEM.

blunted in sleep-restricted mice (Fig. $4 D, E$ ), suggesting an absence of sleep compensation in these mice. Furthermore, we observed that the effects of sleep restriction on sleep homeostasis were still present 2 weeks after the termination of sleep restriction (Fig. 4F-I). Collectively, the findings that sleep-restricted mice exhibit reduced SWA rebound and lack of sleep compensation in response to acute sleep deprivation suggest that sleep homeostasis is impaired after chronic sleep restriction.

Chronic sleep restriction impairs the homeostatic adenosine response to prolonged wakefulness

Presynaptic inhibition mediated by tonic adenosine acting on A1Rs (adenosine tone) provides basal inhibition of synaptic transmission
(Pascual et al., 2005). The concentration of extracellular adenosine and its relative increase in response to wakefulness is correlated with SWA and similarly drives sleep need (Basheer et al., 2004). This wakefulness-dependent increase in adenosine peaks before sleep onset and is thought to inhibit cholinergic projections of the brainstem and basal forebrain regions to promote sleep. Although similar increases in adenosine have been reported to occur in basal forebrain as well as cortex (Kalinchuk et al., 2011), and more recently, in the hippocampus (Schmitt et al., 2012) in response to spontaneous wakefulness and short-term sleep deprivation, the effect of prolonged sleep disruption on adenosine tone is not known.

To examine the impact of chronic sleep restriction on the wakefulness-induced accumulation of adenosine, acute hip- 
A
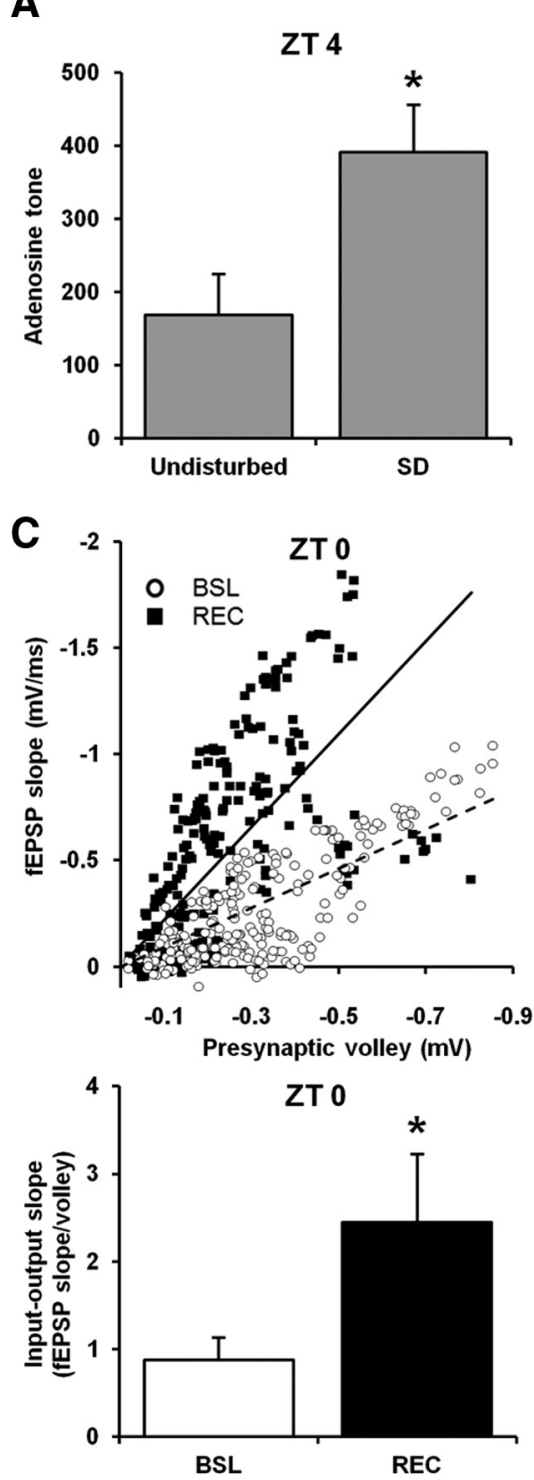

B
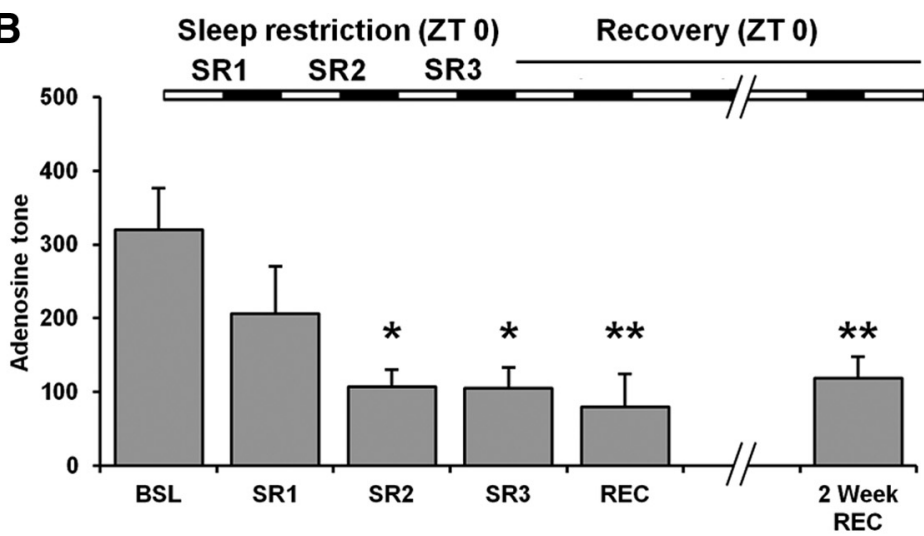

D
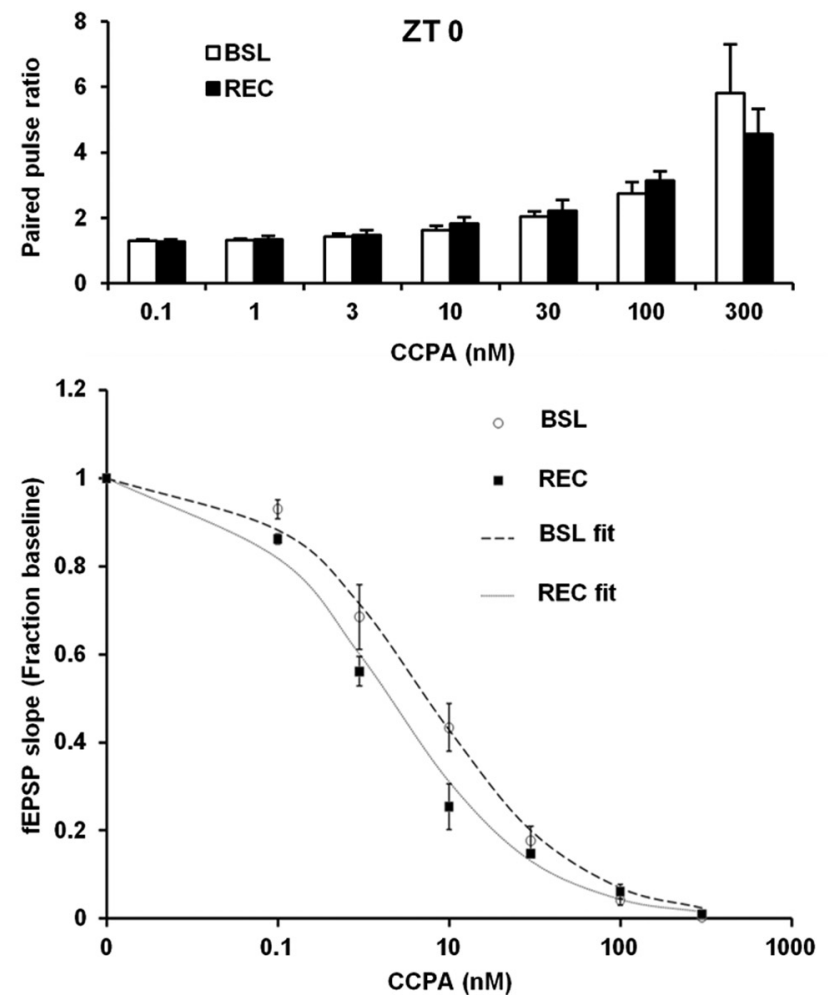

Figure 5. Sleep restriction inactivates wakefulness-dependent elevation of extracellular adenosine. $\boldsymbol{A}$, Adenosine tone was significantly higher in hippocampal slices taken from mice that had been sleep deprived for $4 \mathrm{~h}$ (SD) on the treadmill compared with slices taken from undisturbed controls (Mann-Whitney $U$ test: $U=0.00,{ }^{*} p<0.05 ; n=5$ per group). $\boldsymbol{B}$, Compared with slices taken from nonsleep-restricted control mice (BSL) $(n=6), 3$ consecutive days of sleep restriction (SR1, $n=4 ; S R 2, n=4 ; S R 3, n=4)$ produced a progressive reduction in the level of adenosine tone, measured after each day of sleep restriction at ZTO. This reduced adenosine tone persisted after a recovery period of $24 \mathrm{~h}(\mathrm{REC}, n=6)$ and 2 weeks $(2$ week REC, $n=6$; group comparison of sleep restriction/recovery with baseline: $p<0.01$, Kruskal-Wallis ANOVA, $H=10.51$; Mann-Whitney posthoc test, $\left.{ }^{*} p<0.05,{ }^{* *} p<0.01\right)$. C, Top, The synaptic input/output response measured at ZTO was reduced in slices from BSL mice compared with those from the REC group. In response to increasing stimulation, the fEPSP slope relative to presynaptic volley showed a greater response to similar axonal input (linear fit across recordings during BSL: $y=0.92 x, r^{2}=0.63$; linear fit across recordings during REC: $2.19 x, r^{2}=0.34 ; n=6$ per group). Bottom, The slopes estimated from individual linear fits of input/output curves were significantly increased in REC mice relative to BSL controls (unpaired Student's $t$ test, $t=-2.48,{ }^{*} p<0.05, n=6$ per group). D, Sensitivity to presynaptic inhibition by A1Rs was assessed using increasing concentrations of the agonist CCPA (from 0.1 to $300 \mathrm{~nm}$ ). Sensitivity was not reduced in slices taken from REC mice compared with slices taken from BSL mice. Sleep-restricted and control mice show similar levels of paired pulse facilitation (top, two-way repeated-measures ANOVA, condition, $F=0.06, p>0.05$, concentration, $F=9.92, p<$ 0.001 ; condition $\times$ concentration, $F=0.30, p>0.05, n=5$ for each group) and synaptic inhibition (bottom; Hill plot fit of reduction in fEPSP slope relative to baseline; REC: $I_{50}=4 \mathrm{~nm} ; B S_{L}: I_{50}$ $=10 \mathrm{~nm} ; n=5$ for each group) for all concentrations of (CPA. The $n$ value indicates the number of animals ( 1 slice per animal). Error bars represent SEM.

pocampal slices were isolated from mice at multiple time points across the $3 \mathrm{~d}$ of sleep restriction. During the first day of sleep restriction (SR1), there was a significant increase in adenosine tone at ZT4, after the first cycle of treadmill activity (SD), relative to adenosine levels at ZT4 in undisturbed mice (Fig. 5A). This is consistent with previous studies in which adenosine tone was increased following $4 \mathrm{~h}$ of sleep deprivation using gentle handling (Schmitt et al., 2012). In contrast, chronic sleep restriction reduced the adenosine tone measured at the normal onset of sleep (ZT0) on each of the subsequent days of sleep restriction (Fig. 5B). Moreover, the reduction in adenosine tone was maintained after $24 \mathrm{~h}$ recovery sleep (Fig. 5B). In addition, this effect was sustained for at least 2 weeks after the termination of sleep restriction (Fig. $5 B$ ). The attenuated level of synaptic inhibition following sleep restriction was also evident in the input/output curve of the baseline fEPSP response (Fig. $5 C$ ). In slices taken at ZT0, the fEPSP response as a function of presynaptic volley was greater in sleep-restricted mice compared with undisturbed mice (Fig. 5C, top). The linear fit estimation of the 

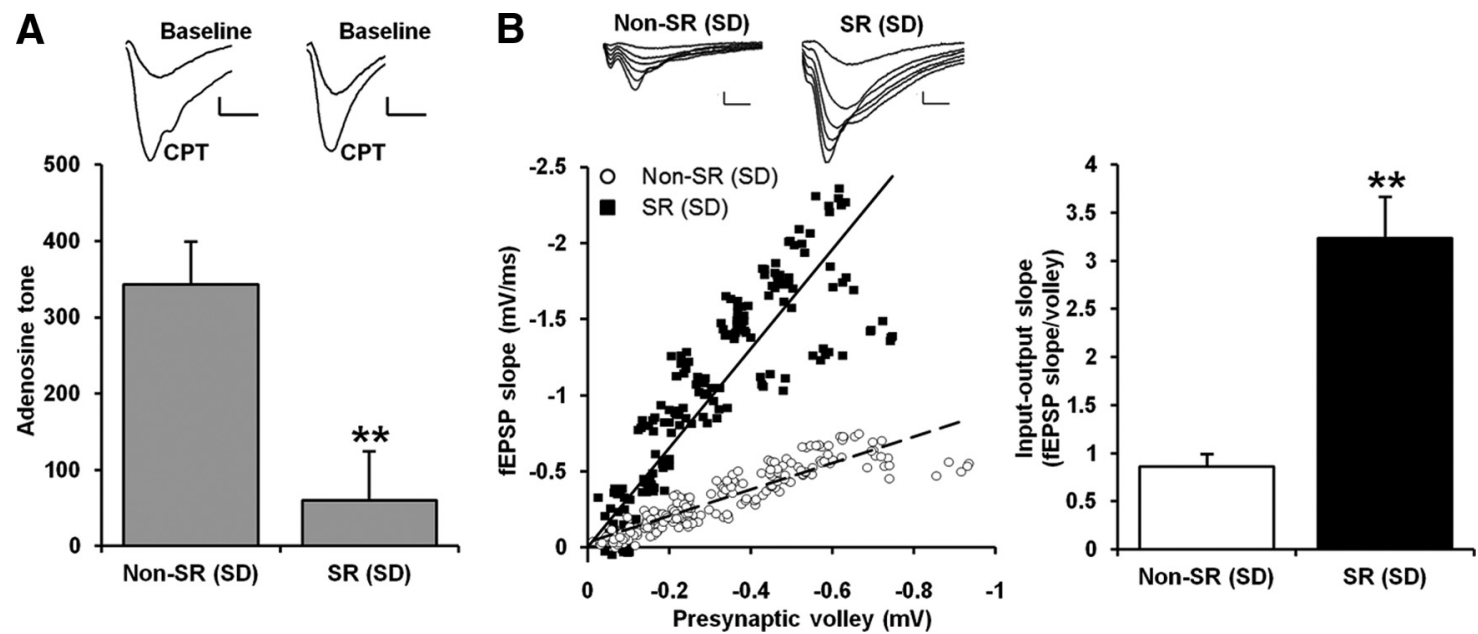

Figure 6. Prior sleep restriction significantly suppresses the sleep deprivation-dependent increase in adenosine-mediated inhibition. $\boldsymbol{A}$, Significantly lower adenosine tone is observed in previously SR mice compared with Non-SR controls following $6 \mathrm{~h}$ of SD (Mann-Whitney $U$ test, $U=0.00$ : ** $p<0.01, n=5$ per group). Insets, The average of fEPSPs before (baseline) and during application of $200 \mathrm{~nm}$ CPT in non-SR (left) and SR mice (right) after $6 \mathrm{~h} \mathrm{SD}$. Scale bars, $0.2 \mathrm{mV}, 2.5 \mathrm{~ms}$. B, Left, Following SD, the input- output curve in SR mice shows an apparent increase compared with non-SR mice. In response to increasing stimulation, the fEPSP slope relative to presynaptic volley showed a greater response to similar axonal input in slices from SR mice (linear fit across recordings in non-SR mice: $y=0.94 \mathrm{x}, r^{2}=0.80$; linear fit across recordings in SR mice: $y=3.26 \mathrm{x}, r^{2}=0.72 ; n=6$ per group). Insets, The average of fEPSPs in response to currents of increasing intensity in non-SR (left) and SR mice (right) after $6 \mathrm{~h} \mathrm{SD}$. Scale bars, $0.2 \mathrm{mV}, 2.5 \mathrm{~ms}$. Right, The slopes estimated from individual linear fits of input/output curves were significantly increased in SR mice relative to non-SR controls (Tukey's HSD test, $q=3.61,{ }^{* *} p<0.01, n=6$ per group). The $n$ value indicates the number of animals (1 slice per animal). Error bars represent SEM.

slope of input/output curves from slices at this time point showed a significant increase in slices from sleep-restricted mice relative to undisturbed controls (Fig. 5C, bottom).

Because adenosine tone depends both on extracellular adenosine levels and A1R surface expression, we next determined whether the reduction was due to a decrease in A1R sensitivity. Dose-response measurements of the A1R agonist, CCPA (0.1$330 \mathrm{nM}$ ), indicated a modest, though not significant, increase in A1R sensitivity in hippocampi from sleep-restricted mice $\left(\mathrm{IC}_{50}=\right.$ $4 \mathrm{~nm}$; Fig. 5D, bottom) relative to undisturbed control mice $\left(\mathrm{IC}_{50}=10 \mathrm{nM}\right.$; Fig. $5 D$, bottom $)$, with no significant change in paired pulse ratios (Fig. $5 D$; top), suggesting that the reduced adenosine tone measurements were not a consequence of downregulated A1R expression or function, but instead involved a reduction in extracellular adenosine acting at the synapse. Together, these results indicate that sleep restriction prevents the increase in adenosine usually associated with normal wakefulness.

To further test whether sleep restriction disrupts the adenosine response to wakefulness, adenosine tone was measured following $6 \mathrm{~h}$ of sleep deprivation in previously undisturbed and sleep-restricted mice. Sleep-restricted mice were allowed $24 \mathrm{~h}$ of recovery after the $3 \mathrm{~d}$ of sleep restriction and then sleep deprived by gentle handling for $6 \mathrm{~h}$. The elevation of adenosine tone following $6 \mathrm{~h}$ of sleep deprivation was significantly blunted in mice that were previously sleep restricted (SR (SD)), compared with undisturbed controls (Non-SR (SD)) (Fig. 6A). Analysis of the input/output curve for synaptic transmission showed that the field responses to increasing stimulation intensity were dramatically larger as a function of presynaptic input in the sleep restricted group (Fig. $6 B$ ). This observation indicates that the greater presynaptic inhibition of synaptic transmission normally observed following sleep deprivation (Schmitt et al., 2012) was prevented by prior sleep restriction and further suggests that no increase in other inhibitory pathways occurs to compensate for the loss of wakefulness-dependent adenosine.

The decrease in wakefulness-dependent adenosine following sleep restriction could either be caused by a reduction in the sources of adenosine or by increased clearance. Adenosine is cleared through passive transport by ENT1 down its concentration gradient (Boison,
2013; Wall and Dale, 2013). To determine whether changes in the rate of clearance through this pathway caused the reduction in tonic adenosine following sleep restriction, we selectively blocked ENT1 with NBMPR (100 nM) and measured the effect on adenosinemediated-synaptic inhibition (Fig. 7).

Consistent with previous results (Pascual et al., 2005), we observed an inhibition of synaptic transmission in response to NBMPR in slices from undisturbed mice (Fig. 7A). This effect was blocked by inhibiting A1Rs using CPT (percentage change in fEPSP slope; without CPT: $-31.34 \pm 5.79 \%, n=6$ slices vs with CPT: $12.91 \pm 6.73 \%, n=5$ slices; Tukey's HSD test, $q=3.27, p<$ $0.05)$, indicating that the synaptic inhibition was due to A1R activation. If the reduction in extracellular adenosine following sleep restriction was due to increased clearance by passive reuptake through ENT1, blocking this transporter should lead to a higher level of A1R-mediated synaptic inhibition. However, we observed a significantly smaller NBMPR-induced synaptic inhibition in slices from sleep-restricted mice (Fig. $7 A, B$ ), suggesting that the lower adenosine tone following sleep restriction is due to a reduction in the source of adenosine. Together, these results support the hypothesis that the allostatic reduction in homeostatic sleep pressure by sleep restriction occurs because wakefulness-dependent changes in the sources of adenosine are dampened.

\section{Sensitivity to alcohol is significantly reduced following chronic sleep restriction}

Recent studies have suggested a role for adenosine signaling pathways in the bidirectional relationship between sleep impairments and alcohol abuse (Nam et al., 2012). Because it is known that alcohol increases adenosine levels (Nagy et al., 1990), which in turn, mediate the motor-impairing effects of alcohol via A1R activation (Dar, 1990, 1993, 2001), we asked whether the sustained reduction in adenosine tone seen in sleep-restricted mice could be correlated with a reduction in the behavioral response to alcohol. Sensitivity to the motor-impairing effects of alcohol was measured 24 h, 2 weeks, and 4 weeks after termination of sleep restriction. All mice were able to remain on the rotarod for at least $60 \mathrm{~s}$ (baseline) before receiving an intoxicating dose of alcohol 

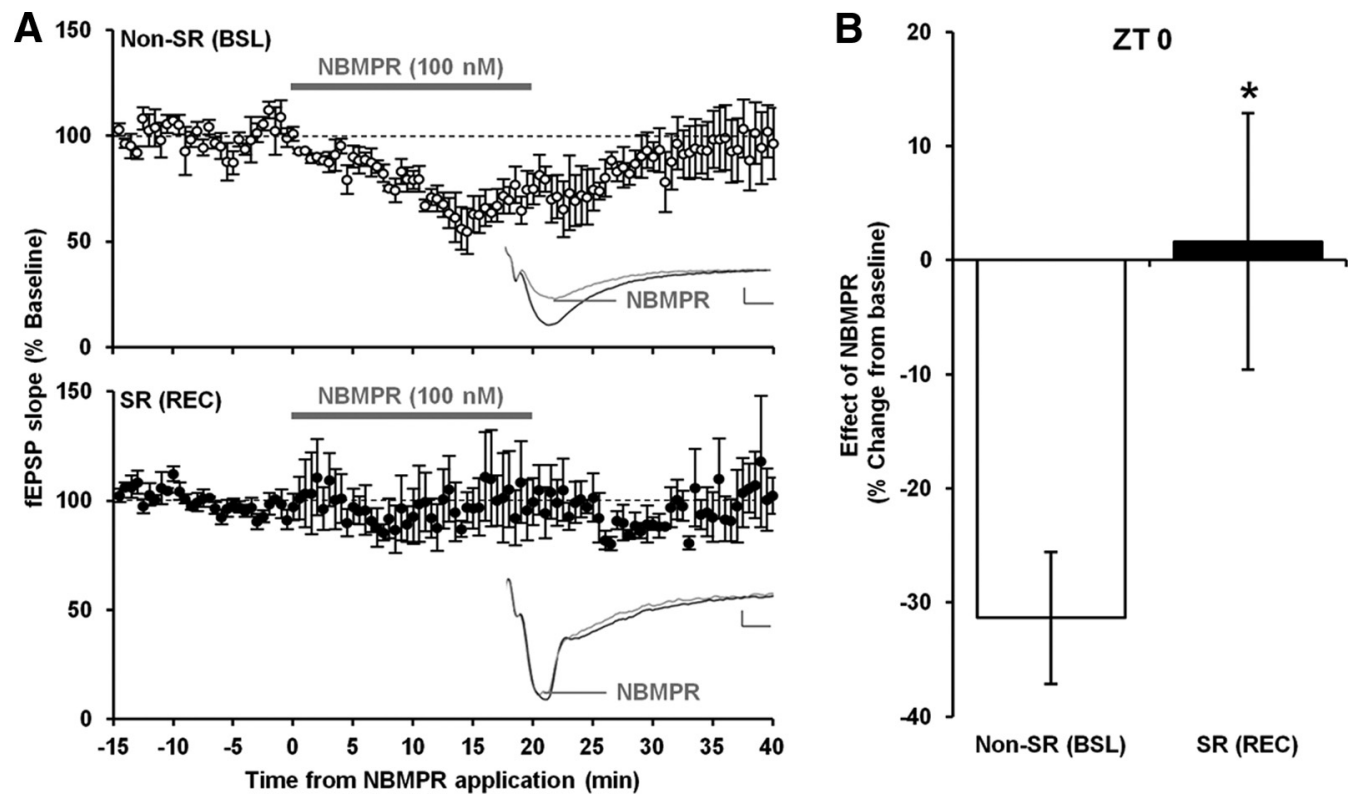

Figure 7. Passive reuptake of adenosine is reduced following sleep restriction. $A$, Blocking passive transport of adenosine through ENT1 with NBMPR (100 nM) produces a marked reduction in fEPSP slope in control slices from non-SR mice (top graph) which was not evident in SR mice (bottom graph). Insets, The average of fEPSPs before (black trace) and during application of $100 \mathrm{~nm} \mathrm{NBMPR}$ (gray trace) in non-SR (top graph) and SR mice (bottom graph). Scale bars, $0.2 \mathrm{mV}, 5 \mathrm{~ms}$. B, Average percentage change of the fEPSP slope in response to NBMPR calculated during the last 5 min of the application period. A significantly greater change in synaptic inhibition was observed in slices from the non-SR group compared with those from the SR group (Tukey's HSD test, $q=4.27^{*} p<$ $0.05, n=5$ per group). The $n$ value indicates the number of animals ( 1 slice per animal). Error bars represent SEM.

$(2.0 \mathrm{~g} / \mathrm{kg}$, i.p.). The latency to fall was measured at $15 \mathrm{~min}$ intervals up to $80 \mathrm{~min}$ postinjection. Performance on the rotarod (measured as latency to fall as a percentage of baseline) was significantly higher in sleep-restricted mice (SR) compared with nonsleep-restricted mice (Non-SR) (Fig. 8A), suggesting that sleeprestricted mice have reduced sensitivity to the motor-impairing effects of alcohol. Given that chronic sleep restriction had a sustained impact on sleep pressure and adenosine tone (Figs. $4 F-I$, $5 B$ ) the mice were reprobed for sensitivity to the motorimpairing effects of alcohol 2 and 4 weeks later. Sleep-restricted mice were still significantly less impaired than nonsleeprestricted mice at each of these time points (Fig. $8 \mathrm{~B}, \mathrm{C}$ ). In agreement with these findings, the time to $50 \%$ recovery of performance was significantly shorter in sleep-restricted mice compared with nonsleep-restricted mice (Fig. 8D). Importantly, this reduced sensitivity persisted in the absence of altered blood alcohol contents (BAC at $24 \mathrm{~h}$ : non-SR, $185.25 \pm 20.17 \mathrm{mg} / \mathrm{dl}$, $n=14$ vs SR, $211.95 \pm 58.78 \mathrm{mg} / \mathrm{dl}, n=19$; BAC at 2 weeks: non-SR, $154.89 \pm 9.65 \mathrm{mg} / \mathrm{dl}, n=23$ vs SR, $147.22 \pm 40.83$ $\mathrm{mg} / \mathrm{dl}, n=31$; BAC at 4 weeks: non-SR, $171.86 \pm 2.88 \mathrm{mg} / \mathrm{dl}, n=$ 14 vs $\mathrm{SR}, 163.74 \pm 45.41 \mathrm{mg} / \mathrm{dl}, n=20$; two-way repeatedmeasures ANOVA: condition, $F=0.08, p>0.05)$, suggesting that the difference in sensitivity was not due to altered alcohol metabolism, but rather was a central response. Furthermore, chronic intracerebroventricular infusion of the A1R antagonist DPCPX decreased sensitivity to the motor-impairing response to alcohol in undisturbed mice (Fig. 8E). However, DPCPX treatment did not further reduce alcohol sensitivity in sleep-restricted mice (Fig. $8 F$ ) or the time to reach $50 \%$ recovery (DPCPX: $32.25 \pm$ $5.42 \mathrm{~min}, n=10$ vs vehicle: $40.93 \pm 5.86 \mathrm{~min}, n=8$; Student's $t$ test: $t=-1.08, p>0.05)$. These results are consistent with the notion that attenuated A1R signaling contributes to reduced alcohol sensitivity in mice that have been chronically sleep restricted.

\section{Discussion}

Chronic sleep restriction leads to an impairment in sleep homeostasis

The physiological consequences of accumulated sleep loss can be sustained for prolonged periods and lead to reductions in attention and cognitive function (Van Dongen et al., 2003; Banks and Dinges, 2007; McCoy and Strecker, 2011). The mechanisms underlying changes in brain function following periods of restricted sleep are unknown. To determine whether sleep homeostasis was significantly modified by $3 \mathrm{~d}$ of sleep restriction, we performed an acute sleep deprivation $(6 \mathrm{~h})$ beginning $24 \mathrm{~h}$ into the recovery period following sleep restriction. This probe test revealed dramatic alterations in the homeostatic response to acute sleep deprivation; sleep-restricted mice did not demonstrate the expected increase in SWA during NREM sleep nor the compensatory increase in sleep time that normally follows sleep deprivation in control nonsleep-restricted mice. Interestingly, the impairment of the sleep homeostat seen in sleep-restricted animals was longlasting (persisting for at least 2 weeks after termination of sleep restriction). During the period of sleep restriction, we found the expected initial increase in SWA during NREM sleep, which declined during the $3 \mathrm{~d}$ sleep-restriction period. Consistent with previous studies (Kim et al., 2007; Deurveilher et al., 2012), these results suggest there is an allostatic response to chronic sleep restriction which impairs the homeostatic response to subsequent sleep deprivation.

Enforced wakefulness increases the levels of adenosine in many brain regions including the basal forebrain, cortex, and hippocampus (Kalinchuk et al., 2011; Schmitt et al., 2012). Because A1R function is required for homeostatic responses to sleep deprivation (Bjorness et al., 2009; Halassa et al., 2009), we asked whether A1R signaling systems were dysregulated by sleep restriction. In agreement with previous reports, acute sleep deprivation (4 h) enhanced adenosine tone (Schmitt et al., 2012). 
A
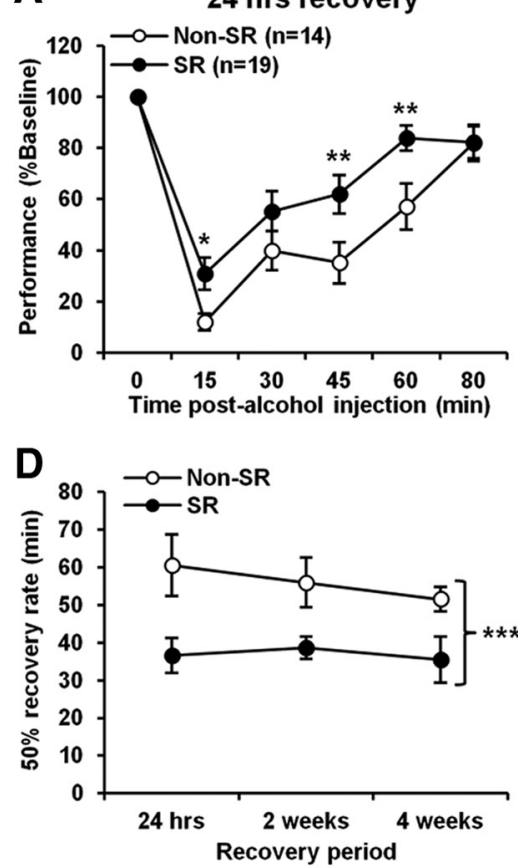

B
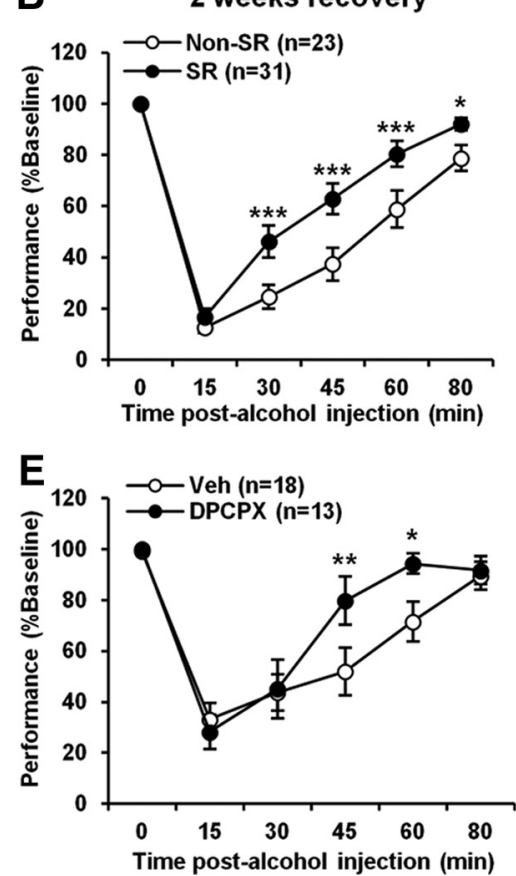

C $\quad 4$ weeks recovery
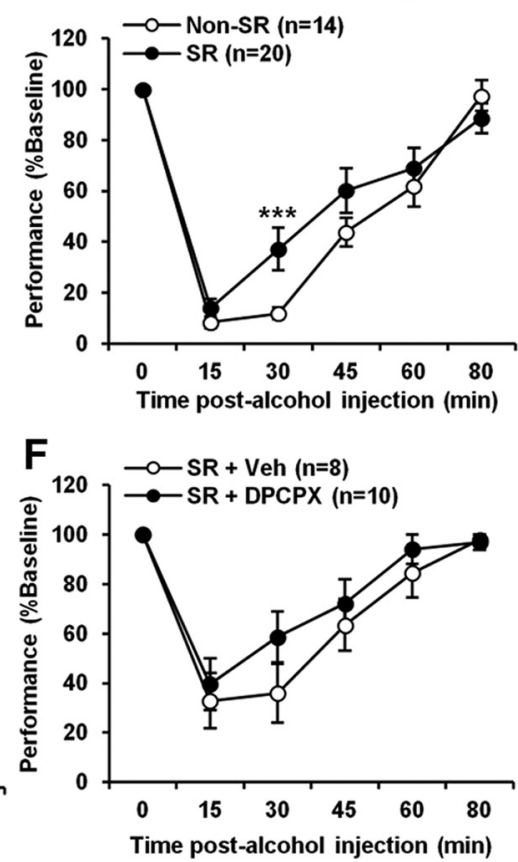

Figure 8. Sensitivity to the motor-impairing effects of alcohol is decreased following chronic sleep restriction, an effect mimicked by blocking A1Rs. $A$, SR mice were significantly less impaired on the rotarod after alcohol injection $(2 \mathrm{~g} / \mathrm{kg}$ ) compared with non-SR when tested $24 \mathrm{~h}$ after termination of sleep restriction (two-way repeated-measures ANOVA: condition, $F=7.00, p<0.05$; time, $F=51.61, p<0.001$; condition $\times$ time, $F=2.40, p<0.05$; Bonferonni post hoc test, $\left.{ }^{*} p<0.05,{ }^{* *} p<0.01\right) . \boldsymbol{B}, \boldsymbol{C}$, The effect persisted when mice were tested 2 weeks later $(\boldsymbol{B}$, two-way repeated-measures ANOVA: condition, $F=13.20, p<0.001$; time, $F=117.97, p<0.001$; condition $\times$ time, $F=3.11, p<0.01$; Bonferonni $p o s t$ hoc test, ${ }^{*} p<0.05$, ${ }^{* * *} p<0.001$ ) and 4 weeks later (C, two-way repeated-measures ANOVA: condition, $F=4.91, p<0.05$; time, $F=72.37, p<0.001$; Bonferonni posthoctest, $\left.{ }^{* * *} p<0.001\right) . \boldsymbol{D}$, Compared with non-SR mice, the time required for mice to reach $50 \%$ recovery rate is significantly less in SR mice (two-way repeated-measures ANOVA: condition, $\left.F=15.30,{ }^{* * *} p<0.001\right)$. $\boldsymbol{E}$, The effect of chronic sleep restriction was mimicked in mice receiving continuous intracerebroventricular infusion of DPCPX (100 $\mu \mathrm{m})$, which were less sensitive to the motor-impairing effects of alcohol compared with vehicle (Veh)-treated mice (two-way repeated-measures ANOVA: condition, $F=1.74, p>0.05$; time, $F=39.95, p<0.001$; condition $\times$ time, $F=2.44, p<0.05$; Bonferonni post hoc test, ${ }^{*} p<0.05$; ${ }^{* *} p<0.01$ ). $F$, In SR mice, continuous intracerebroventricular infusion of DPCPX (100 $\mu \mathrm{M})$ did not further reduce sensitivity to the motor-impairing effects of alcohol compared with vehicle (Veh)-treated mice (two-way repeated-measures ANOVA: condition, $F=0.88, p>0.05$; time, $F=33.36, p<0.001$; condition $\times$ time, $F=0.89, p>0.05$ ). The $n$ value depicted in this figure indicates the number of animals. Error bars represent SEM.

However, the basal adenosine tone in response to spontaneous wakefulness declined during the period of sleep restriction and did not recover following either $24 \mathrm{~h}$ or 2 weeks of recovery; these findings were consistent with the reduction in SWA power measured at the same time points. Moreover, the sleep deprivationinduced increase in adenosine tone was significantly attenuated following sleep restriction, which may provide a mechanism underlying the reduced homeostatic sleep response. These results show a long-term allostatic change in the regulation of adenosine signaling in the brain, demonstrating that wakefulness-dependent adenosine signaling is modified by sleep restriction.

There have been conflicting results concerning the allostatic effect of long-term sleep restriction on sleep homeostasis. Our results are consistent with those reported by Kim et al. (2007), Sportiche et al. (2010), and Deurveilher et al. (2012) who showed a significant attenuation in SWA following sleep restriction. However, a similar study measured SWA in discrete cortical regions (frontal, parietal, and occipital) in rats, and reported that sleep homeostasis remains intact during repeated sleep restriction (Leemburg et al., 2010). These discrepancies may be due to differences in methodology and/or analysis, such as variations in sleep-restriction protocols as well as differences in the methods of EEG analysis. However, consistent with this study (Leemburg et al., 2010), we found a slight, though nonsignificant, increase in SWA (i.e., SWA leakage) during enforced wakefulness on the treadmill. It is important to note that this compensatory increase in SWA during wake remained constant across the $3 \mathrm{~d}$ of sleep restriction, and thus cannot account for the progressive attenuation in NREM SWA during the $2 \mathrm{~h}$ sleep opportunities. In addition, when we analyzed the cumulative integrated SWA in all vigilance states combined, we found an overall decrease during both periods of enforced wakefulness (TM-on) and sleep opportunity (TM-off) throughout the $3 \mathrm{~d}$ of sleep restriction, suggesting that SWA leakage during enforced wakefulness was not sufficient to compensate for the loss of SWA produced by sleep restriction. We also implemented two additional measurements of sleep homeostasis-adenosine tone, which is correlated with SWA power (Halassa et al., 2009; Kalinchuk et al., 2011) and response to acute sleep deprivation- to further probe the consequences of accumulated sleep loss. When these two measures are used, it is clear that under the conditions of our study mice do exhibit an allostatic suppression of the sleep homeostat in response to sleep restriction.

\section{Sleep restriction disrupts wakefulness-dependent changes in adenosine}

Several sources contribute to the accumulation of adenosine in the extracellular space including direct release from nerve terminals (Wall and Dale, 2008), passive release through equilibrative nucleoside transporters ENT1 and hydrolysis of extracellular ATP (Wall and Dale, 2013). Recent studies using conditional astrocyte-specific transgenic mice have shown that ATP released from astrocytes is the dominant source of the adenosine contributing to sleep homeostasis (Fellin et al., 2009; Halassa et al., 2009; 
Schmitt et al., 2012). To discriminate between reduced supply of extracellular adenosine and increased adenosine uptake, we added the ENT1 inhibitor NBMPR to brain slices. We observed that previously sleep-restricted mice had a diminished response to NBMPR, which supports the idea that sleep restriction leads to a reduction in the source of extracellular adenosine rather than an increase in its clearance. Although these results suggest that higher intracellular metabolism of adenosine is not responsible for the effects of sleep restriction, enzymes involved in its extracellular metabolism, such as $5^{\prime}$-ectonucleotidase (CD73) and adenosine deaminase, may still play a role (Bachmann et al., 2012; Zielinski et al., 2012), as could ADK if it is able to access adenosine through an NBMPR-independent pathway (Greene, 2011; Boison, 2013). Future studies will be required to conclusively discriminate between these mechanisms.

\section{Impaired sleep homeostasis alters sensitivity to alcohol}

Recovering alcoholics often suffer severe sleep impairments that are reportedly a high predictor of relapse (Brower and Perron, 2010). Interestingly, a clinical study recently reported that recovering alcoholics fail to respond to acute sleep deprivation (Armitage et al., 2012). Because of these reports and given that adenosine is a known mediator of behavioral effects of alcohol (Nagy et al., 1990; Diamond et al., 1991; Nam et al., 2012), we asked whether sleep restriction and the attendant long-term changes in adenosine signaling and sleep homeostasis might induce alterations in behavioral responses to alcohol. We examined this possibility by measuring sensitivity to the motor-impairing effect of alcohol, because insensitivity to alcohol is a strong predictor of alcohol abuse later in life (Schuckit, 1994). Our results indicate that chronic sleep restriction significantly reduced sensitivity to the motor-impairing effects of alcohol, an effect that was sustained for at least 4 weeks after sleep restriction.

Our results showing a sustained reduction in NREM SWA, adenosine tone, and sensitivity to alcohol following chronic sleep restriction are especially interesting in light of evidence pointing to adenosine as a mediator of the effects of alcohol (Dar, 1993; Diamond and Gordon, 1994; Nam et al., 2012). Ethanol increases adenosine by blocking the equilibrative nucleoside transporter ENT1 (Nagy et al., 1990), and mice lacking ENT1 have reduced adenosine tone and reduced sensitivity to alcohol (Choi et al., 2004). Ethanol-induced changes in adenosine levels can subsequently act on either A1 or A2A receptors (Clark and Dar, 1988; Dar, 1990, 2001; Micioni Di Bonaventura et al., 2012). Given the bidirectional comorbidity between sleep disorders and chronic alcohol use, our findings pose the intriguing possibility that the adenosine A1R pathway that drives sleep pressure acts on a parallel pathway that contributes to the intoxicating effects of alcohol. One potential concern with this interpretation is that the changes in adenosine we measure occur in the hippocampus, a structure not generally considered to play a role in the motor impairing effects of alcohol. In previous studies (Schmitt et al., 2012), however, we have observed that similar changes in adenosine occur in both the hippocampus and cortex in response to acute sleep deprivation, suggesting that wakefulness-dependent mechanisms controlling tonic adenosine are broadly similar in multiple brain regions. This hypothesis is further supported by the observation that blocking A1Rs globally is sufficient to replicate the effects of chronic sleep restriction on the sensitivity to alcohol, but does not further reduce alcohol sensitivity in sleeprestricted mice. Together these observations suggest a model in which perturbation of sleep homeostasis causes subsequent im- pairments in sleep pressure by decreasing tonic adenosine leading to reduced A1R signaling and decreased sensitivity to alcohol.

\section{Conclusion}

We show that chronic sleep restriction has a sustained impact on sleep homeostasis leading to an attenuated response to sleep deprivation after termination of sleep restriction. We identified reduced A1R signaling as one mechanism underlying this allostatic response by showing that sleep restriction causes a sustained impairment in sources of adenosine, which are critically involved in the modulation of sleep homeostasis. Because alcohol and wakefulness are known to have convergent actions in the control of extracellular adenosine, we also asked whether sleep restriction would affect behavioral sensitivity to alcohol exposure. We observed a novel behavioral impact of long-term sleep disruption, demonstrating that sleep restriction reduced behavioral sensitivity to alcohol. To our knowledge, this is the first demonstration that adenosine is involved in the long-lasting effects of chronic sleep restriction on sleep homeostasis and the behavioral response to alcohol.

\section{References}

Armitage R (2007) Sleep and circadian rhythms in mood disorders. Acta Psychiatr Scand Suppl 433:104-115. Medline

Armitage R, Hoffmann R, Conroy DA, Arnedt JT, Brower KJ (2012) Effects of a 3-hour sleep delay on sleep homeostasis in alcohol dependent adults. Sleep 35:273-278. CrossRef Medline

Arrigoni E, Rainnie DG, McCarley RW, Greene RW (2001) Adenosinemediated presynaptic modulation of glutamatergic transmission in the laterodorsal tegmentum. J Neurosci 21:1076-1085. Medline

Bachmann V, Klaus F, Bodenmann S, Schäfer N, Brugger P, Huber S, Berger W, Landolt HP (2012) Functional ADA polymorphism increases sleep depth and reduces vigilant attention in humans. Cereb Cortex 22:962970. CrossRef Medline

Banks S, Dinges DF (2007) Behavioral and physiological consequences of sleep restriction. J Clin Sleep Med 3:519-528. Medline

Basheer R, Strecker RE, Thakkar MM, McCarley RW (2004) Adenosine and sleep-wake regulation. Prog Neurobiol 73:379-396. CrossRef Medline

Bjorness TE, Kelly CL, Gao T, Poffenberger V, Greene RW (2009) Control and function of the homeostatic sleep response by adenosine A1 receptors. J Neurosci 29:1267-1276. CrossRef Medline

Boison D (2013) Adenosine kinase: exploitation for therapeutic gain. Pharmacol Rev 65:906-943. CrossRef Medline

Borbély AA, Achermann P (1999) Sleep homeostasis and models of sleep regulation. J Biol Rhythms 14:557-568. Medline

Brower KJ (2003) Insomnia, alcoholism and relapse. Sleep Med Rev 7:523539. CrossRef Medline

Brower KJ, Perron BE (2010) Sleep disturbance as a universal risk factor for relapse in addictions to psychoactive substances. Med Hypotheses 74: 928-933. CrossRef Medline

Brower KJ, Aldrich MS, Robinson EA, Zucker RA, Greden JF (2001) Insomnia, self-medication, and relapse to alcoholism. Am J Psychiatry 158:399404. CrossRef Medline

Brower KJ, Krentzman A, Robinson EA (2011) Persistent insomnia, abstinence, and moderate drinking in alcohol-dependent individuals. Am J Addict 20:435-440. CrossRef Medline

Bruns RF (1981) Adenosine antagonism by purines, pteridines and benzopteridines in human fibroblasts. Biochem Pharmacol 30:325-333. CrossRef Medline

Choi DS, Cascini MG, Mailliard W, Young H, Paredes P, McMahon T, Diamond I, Bonci A, Messing RO (2004) The type 1 equilibrative nucleoside transporter regulates ethanol intoxication and preference. Nat Neurosci 7:855-861. CrossRef Medline

Cirelli C (2009) The genetic and molecular regulation of sleep: from fruit flies to humans. Nat Rev Neurosci 10:549-560. CrossRef Medline

Clark M, Dar MS (1988) Mediation of acute ethanol-induced motor disturbances by cerebellar adenosine in rats. Pharmacol Biochem Behav 30: 155-161. Medline

Dar MS (1990) Central adenosinergic system involvement in ethanol- 
induced motor incoordination in mice. J Pharmacol Exp Ther 255:12021209. Medline

Dar MS (1993) Brain adenosinergic modulation of acute ethanol-induced motor impairment. Alcohol Alcohol Suppl 2:425-429. Medline

Dar MS (2001) Modulation of ethanol-induced motor incoordination by mouse striatal A(1) adenosinergic receptor. Brain Res Bull 55:513-520. CrossRef Medline

Deurveilher S, Rusak B, Semba K (2012) Time-of-day modulation of homeostatic and allostatic sleep responses to chronic sleep restriction in rats. Am J Physiol Regul Integr Comp Physiol 302:R1411-14R25. CrossRef Medline

Diamond I, Gordon AS (1994) The role of adenosine in mediating cellular and molecular responses to ethanol. EXS 71:175-183. Medline

Diamond I, Nagy L, Mochly-Rosen D, Gordon A (1991) The role of adenosine and adenosine transport in ethanol-induced cellular tolerance and dependence: possible biologic and genetic markers of alcoholism. Ann N Y Acad Sci 625:473-487. CrossRef Medline

Fellin T, Halassa MM, Terunuma M, Succol F, Takano H, Frank M, Moss SJ, Haydon PG (2009) Endogenous nonneuronal modulators of synaptic transmission control cortical slow oscillations in vivo. Proc Natl Acad Sci U S A 106:15037-15042. CrossRef Medline

Greene RW (2011) Adenosine: front and center in linking nutrition and metabolism to neuronal activity. J Clin Invest 121:2548-2550. CrossRef Medline

Halassa MM, Florian C, Fellin T, Munoz JR, Lee SY, Abel T, Haydon PG, Frank MG (2009) Astrocytic modulation of sleep homeostasis and cognitive consequences of sleep loss. Neuron 61:213-219. CrossRef Medline

Hanlon EC, Vyazovskiy VV, Faraguna U, Tononi G, Cirelli C (2011) Synaptic potentiation and sleep need: clues from molecular and electrophysiological studies. Curr Top Med Chem 11:2472-2482. CrossRef Medline

Kalinchuk AV, McCarley RW, Porkka-Heiskanen T, Basheer R (2011) The time course of adenosine, nitric oxide (NO) and inducible NO synthase changes in the brain with sleep loss and their role in the non-rapid eye movement sleep homeostatic cascade. J Neurochem 116:260-272. CrossRef Medline

Kim Y, Laposky AD, Bergmann BM, Turek FW (2007) Repeated sleep restriction in rats leads to homeostatic and allostatic responses during recovery sleep. Proc Natl Acad Sci U S A 104:10697-10702. CrossRef Medline

Leemburg S, Vyazovskiy VV, Olcese U, Bassetti CL, Tononi G, Cirelli C (2010) Sleep homeostasis in the rat is preserved during chronic sleep restriction. Proc Natl Acad Sci U S A 107:15939-15944. CrossRef Medline

McCoy JG, Strecker RE (2011) The cognitive cost of sleep lost. Neurobiol Learn Mem 96:564-582. CrossRef Medline

Micioni Di Bonaventura MV, Cifani C, Lambertucci C, Volpini R, Cristalli G, Froldi R, Massi M (2012) Effects of $\mathrm{A}_{2} \mathrm{~A}$ adenosine receptor blockade or stimulation on alcohol intake in alcohol-preferring rats. Psychopharmacology (Berl) 219:945-957. CrossRef Medline

Nagy LE, Diamond I, Casso DJ, Franklin C, Gordon AS (1990) Ethanol increases extracellular adenosine by inhibiting adenosine uptake via the nucleoside transporter. J Biol Chem 265:1946-1951. Medline

Nam HW, McIver SR, Hinton DJ, Thakkar MM, Sari Y, Parkinson FE, Haydon PG, Choi DS (2012) Adenosine and glutamate signaling in neuronglial interactions: implications in alcoholism and sleep disorders. Alcohol Clin Exp Res 36:1117-1125. CrossRef Medline
Pascual O, Casper KB, Kubera C, Zhang J, Revilla-Sanchez R, Sul JY, Takano H, Moss SJ, McCarthy K, Haydon PG (2005) Astrocytic purinergic signaling coordinates synaptic networks. Science 310:113-116. CrossRef Medline

Schmitt LI, Sims RE, Dale N, Haydon PG (2012) Wakefulness affects synaptic and network activity by increasing extracellular astrocyte-derived adenosine. J Neurosci 32:4417-4425. CrossRef Medline

Schuckit MA (1994) Low level of response to alcohol as a predictor of future alcoholism. Am J Psychiatry 151:184-189. Medline

Sportiche N, Suntsova N, Methippara M, Bashir T, Mitrani B, Szymusiak R, McGinty D (2010) Sustained sleep fragmentation results in delayed changes in hippocampal-dependent cognitive function associated with reduced dentate gyrus neurogenesis. Neuroscience 170:247-258. CrossRef Medline

Steriade M (2005) In: Principles and practices of sleep medicine (Kryger MH, Roth T, Dement WC, eds.), pp 101-119. Philadelphia, PA: Elsevier.

Steriade M, McCarley RW (2005) Brain control of wakefulness and sleep, Ed 2. New York: Plenum.

Tononi G, Cirelli C (2006) Sleep function and synaptic homeostasis. Sleep Med Rev 10:49-62. CrossRef Medline

Van Dongen HP, Maislin G, Mullington JM, Dinges DF (2003) The cumulative cost of additional wakefulness: dose-response effects on neurobehavioral functions and sleep physiology from chronic sleep restriction and total sleep deprivation. Sleep 26:117-126. Medline

Vanderwolf CH (1969) Hippocampal electrical activity and voluntary movement in the rat. Electroencephalogr Clin Neurophysiol 26:407-418. Medline

Vyazovskiy VV, Cirelli C, Pfister-Genskow M, Faraguna U, Tononi G (2008) Molecular and electrophysiological evidence for net synaptic potentiation in wake and depression in sleep. Nat Neurosci 11:200-208. CrossRef Medline

Vyazovskiy VV, Olcese U, Lazimy YM, Faraguna U, Esser SK, Williams JC, Cirelli C, Tononi G (2009) Cortical firing and sleep homeostasis. Neuron 63:865-878. CrossRef Medline

Wall M, Dale N (2008) Activity-dependent release of adenosine: a critical re-evaluation of mechanism. Curr Neuropharmacol 6:329-337. CrossRef Medline

Wall MJ, Dale N (2013) Neuronal transporter and astrocytic ATP exocytosis underlie activity-dependent adenosine release in the hippocampus. J Physiol 591:3853-3871. CrossRef Medline

Whishaw IQ (1972) Hippocampal electroencephalographic activity in the Mongolian gerbil during behaviours and wheel running and in the rat during wheel running and conditioned immobility. Can J Psychol 26: 219-239. Medline

Wong MM, Brower KJ, Nigg JT, Zucker RA (2010) Childhood sleep problems, response inhibition, and alcohol and drug outcomes in adolescence and young adulthood. Alcohol Clin Exp Res 34:1033-1044. CrossRef Medline

Wulff K, Gatti S, Wettstein JG, Foster RG (2010) Sleep and circadian rhythm disruption in psychiatric and neurodegenerative disease. Nat Rev Neurosci 11:589-599. CrossRef Medline

Zielinski MR, Taishi P, Clinton JM, Krueger JM (2012) 5'-Ectonulceotidaseknock-out mice lack non-REM sleep responses to sleep deprivation. Eur J Neurosci 35:1789-1798. CrossRef Medline 